NBER WORKING PAPER SERIES

\title{
'RISKY HABITS' AND THE MARGINAL PROPENSITY TO CONSUME OUT OF PERMANENT INCOME, OR, HOW MUCH WOULD A PERMANENT TAX CUT BOOST JAPANESE CONSUMPTION?
}

\author{
Christopher D. Carroll \\ Working Paper 7839 \\ http://www.nber.org/papers/w7839
NATIONAL BUREAU OF ECONOMIC RESEARCH 1050 Massachusetts Avenue
Cambridge, MA 02138
August 2000

I am grateful to Larry Summers for stimulating my interest in the relationship between the theory of precautionary saving and tax policy in Japan. The usage of the term 'Risky Habits' in the title of this paper is borrowed from a similar usage by Fuhrer and Klein (1998). This paper has benefitted from comments by seminar participants at the first International Economic Journal Annual conference in Seoul, the Brookings Institution, Johns Hopkins University, Harvard University, the University of Cyprus, and Koc University. The views expressed herein are those of the author and do not necessarily reflect the views of the National Bureau of Economic Research.

(C) 2000 by Christopher D. Carroll. All rights reserved. Short sections of text, not to exceed two paragraphs, may be quoted without explicit permission provided that full credit, including (C) notice, is given to the source. 
'Risky Habits' and the Marginal Propensity to Consume Out of Permanent Income, or, How Much Would a Permanent Tax Cut Boost Japanese Consumption?

Christopher D. Carroll

NBER Working Paper No. 7839

August 2000

JEL No. D11, D81, D91, E10, e17, E21, H31

\begin{abstract}
$\underline{\text { ABSTRACT }}$
Papers in variety of disparate literatures have recently suggested that habit formation in consumption may explain several empirical puzzles, ranging from the level and cyclical variability of the equity premium (Abel (1990,1999); Constantinides (1990); Jermann (1998); Campbell and Cochrane (1999)) to the "excess smoothness" of aggregate consumption (Fuhrer (2000)) to the apparent fact that increases in economic growth cause subsequent increases in aggregate saving rates (Carroll and Weil (1994); Bosworth (1993); Attanasio, Picci, and Scorcu (2000); Rodrik (1999); Loayza, Schmidt-Hebbel, and Servén (2000)). This paper examines an implication of these models that has mostly been overlooked: Habits strong enough to solve these puzzles imply an immediate marginal propensity to consume out of permanent shocks of much less than one. When the model is calibrated to roughly match the rise in the Japanese saving rate over the postwar period, it implies that the immediate MPC out of permanent tax cuts may be as low as 30 percent, suggesting that calls for permanent income tax cut as a quick means of stimulating aggregate demand in Japan may be misguided.
\end{abstract}

\author{
Christopher D. Carroll \\ Department of Economics \\ The John Hopkins University \\ Baltimore, MD 21218-2685 \\ and NBER \\ ccarroll@jhu.edu
}




\section{Introduction}

A common textbook example of how economic theory can be used to guide policy comes in the relationship between tax cuts and household spending. Standard versions of the Permanent Income theory of consumption imply that the marginal propensity to consume out of transitory shocks to income is close to zero, while the marginal propensity to consume out of permanent shocks is close to (or equal to) one. Thus, economic policymakers are advised that if they wish to stimulate consumption via an income tax cut, they should make it permanent. While policymakers do not always heed this advice, ${ }^{1}$ economists in the business of making policy recommendations usually express little doubt about its sagacity.

The point of this paper is that the economics profession's traditional confidence that the MPC out of permanent tax cuts is close to one may be misplaced. ${ }^{2}$ The potential problem is that the model which produces the implication of an MPC of one does not allow for habits in consumption. A host of recent papers have argued that models with habits are more consistent with, variously, the short-term dynamics of aggregate consumption in the U.S. and other countries (Fuhrer (2000); Fuhrer and Klein (1998)); the level of the equity premium (Abel (1990, 1999); Constantinides (1990); Jermann (1998)); the cyclical properties of asset prices (Campbell and Cochrane (1999)); and the longterm behavior of aggregate saving rates in Japan and other East Asian countries which have experienced increasing saving rates in the wake of their takeoffs into rapid growth (Carroll and Weil (1994); Carroll, Overland, and Weil (2000)). Most of these papers have proposed habit formation to explain puzzles that seem to have little to do with the marginal propensity to consume out of permanent income. ${ }^{3}$ But this paper argues that habits strong enough to solve these other puzzles imply an MPC out of permanent shocks of much less than one. Alternatively, a credible empirical measurement of an MPC out of permanent shocks that is close to one would constitute a blow to the proposition that habit formation is the right explanation of these other puzzles.

The intuition for why habits generate a low MPC is simple: Habits tend to pull consumption in the direction of its past level (to borrow a metaphor from monetary economics, they make consumption 'sticky'). Delving a bit deeper into the logic, habits make the level of consumption sluggish essentially because they imply that utility is affected not only by the level of consumption but also by consumption growth. Just as the traditional model without habits implies that the level of consumption should be smoothed, habits imply that consumption growth should be smoothed. Thus, in response, say, to a positive shock to permanent income, the same amount of cumulative total increase

\footnotetext{
${ }^{1}$ A recent example is President Bush's 1992 attempt to stimulate consumer spending by reducing the rate at which taxes are withheld from paychecks, without changing statutory tax rates.

${ }^{2}$ The traditional definition of the marginal propensity to consume out of $x$ is the immediate change in consumption induced by a change in $x$; thus, asserting that the MPC out of permanent shocks is less than one does not violate an intertemporal budget constraint that requires that changes in income must eventually be reflected in consumption.

${ }^{3}$ The exception is the work by Fuhrer (2000) who is explicitly concerned with matching the dynamic response of aggregate consumption to shocks, of which permanent tax cuts are but one example.
} 
in consumption will yield more utility if that change is spread out over an extended period of smoothly higher-than-normal growth than if the entire response is concentrated into a single growth spike that happens instantly when the good news arrives (as would happen in the standard model).

One country where the question of the magnitude of the marginal propensity to consume out of permanent tax cuts is a critical policy issue at the moment is Japan, where there is widespread agreement that some form of fiscal and/or monetary stimulus might help lift the economy out of the stagnation of the past decade. Permanent income tax cuts are one of the most widely recommended policies among the advocates of fiscal stimulus. However, Japan is a leading example of a country where rapid growth seems to have stimulated subsequent increases in the saving rate, ${ }^{4}$ a pattern of behavior that appears to be inconsistent with the standard permanent income model but that Carroll, Overland, and Weil (2000) suggest can be explained by habit formation. As a way of organizing the theoretical question around a concrete example, this paper therefore examines a habit formation model parameterized to roughly match the increase in saving in Japan and shows that the MPC out of permanent tax cuts is somewhere in the neighborhood of 30 percent in that model - leading to the conclusion that even permanent income tax cuts may not be an effective way to stimulate aggregate demand quickly in Japan.

The rest of the paper is organized as follows. Section 2 describes the model, which is an extension (incorporating permanent income and shocks thereto) of the growth model with habits in Carroll, Overland, and Weil (2000). Section 3 parameterizes the model both in the baseline case where habits are unimportant and in the case where habits matter. Section 4 shows that the model without habits has trouble explaining the rise in the saving rate, to world-beating highs, that took place in Japan from the mid-1950s to the mid-1970s. However, when habits are added the model becomes much more capable of predicting that increases in growth cause increases in saving as apparently seen in Japan and other East Asian countries. ${ }^{5}$ Section 5 examines the implications of the two models (without habits and with them) for the MPC out of permanent shocks, and shows that the implication of the habit formation model of a low MPC out of permanent shocks is robust. The final section concludes.

\section{Theory}

In theoretical terms, the goal in this paper is to take the model of economic growth with habit formation described in Carroll, Overland, and Weil (2000) (henceforth C-O-W) and enrich it sufficiently so that we can derive implications of habit formation for the marginal propensity to consume out of stochastic permanent shocks to noncapital income. Since the

\footnotetext{
${ }^{4}$ Although Hayashi (1986) argues that the official statistics overstate the level of the saving rate in Japan, even after making the adjustments that Hayashi proposes, the saving rate increases greatly over time.

${ }^{5}$ And elsewhere: Attanasio, Picci, and Scorcu (2000) and Rodrik (1999) find evidence that increases in growth cause increases in saving across the whole swath of countries included in the World Bank's new dataset on saving and growth around the world.
} 
C-O-W model incorporated neither labor (or broadly, noncapital) income nor uncertainty, the model needs to be modified substantially.

$\mathrm{C}-\mathrm{O}-\mathrm{W}$ assumed that aggregate income was generated by a Rebelo-style $Y=A K$ aggregate production function, in which all aggregate income can be interpreted as capital income. This was done because the assumption of an $A K$ production function simplifies the problem greatly, since labor income is eliminated and the aggregate interest rate is constant. Solving the problem with a more traditional CRS neoclassical production function of the form $Y=F(K, L)$ would have been much harder because to decide the proper level of current consumption the representative agent would have needed to forecast the evolution of wages and interest rates, which depends upon the level of current consumption, and so on recursively. Numerical solution methods are available but extremely cumbersome when habits are involved.

The difficulties posed by adding a realistic treatment of idiosyncratic uncertainty are even greater. The macroeconomics literature has largely used representative agent models not because such models are inherently appealing but because the technical challenges of solving and simulating models with idiosyncratic uncertainty and heterogeneity are formidable when there is a neoclassical aggregate production function. The problem is that the evolution of the capital stock depends in principle upon the entire distribution of savings across households. Because the path of wages and interest rates in a model with a standard neoclassical production function depends on the path of the capital stock, in principle the model contains an $M$-dimensional state variable (the levels of wealth for each of the $M$ consumers). Since the 'curse of dimensionality' makes it difficult to solve models numerically when there are as few as 2 state variables, the problem appears intractable (although Per Krusell and Anthony Smith (1998) have recently shown that it is more tractable than it appears).

Here I will avoid those complexities by assuming that we are examining a small open economy in which wages and interest rates are determined by international factor markets. Thus, the gross rate of return after depreciation is fixed at $R=(1+r)$, the depreciation rate is fixed at $\delta$, and labor income growth is assumed to come from an exogenous improvement in aggregate labor productivity at rate $G=(1+g)$ from one period to the next. Net aggregate income will then simply be $w L+r K$, and gross income will be $w L+(r+\delta) K$.

I assume that each infinitely-lived consumer in this economy is endowed with one unit of labor which is supplied inelastically in an aggregate labor market. The individual consumer's labor income is subject to multiplicative idiosyncratic transitory shocks $\epsilon_{i, t+1}$ such that $E_{t}\left[\tilde{\epsilon}_{i, t+1}\right]=1 .^{6}$ Idiosyncratic 'permanent labor income' is defined as the level of labor income that would obtain for individual $i$ if the transitory shock to labor income took on its mean value of one. Permanent labor income $P_{i, t}$ is also subject to lognormally

\footnotetext{
${ }^{6}$ The notational convention will be that stochastic variables have a $\sim$ over them when their expectation is being taken, but not otherwise, on the grounds that equations where the expectation is being taken are the only kinds of equations where the time period from which the equation is being viewed is wellspecified. Hence we write the transitory shock to labor income in period as $\epsilon_{i, t+1}$ but its expectation as $E_{t}\left[\tilde{\epsilon}_{i, t+1}\right]$.
} 
distributed shocks $N_{i, t+1}$ (again such that $E_{t}\left[\tilde{N}_{i, t+1}\right]=1$ ) in each period; the marginal propensity to consume out of permanent income will be determined by examining the response of consumption to these shocks. ${ }^{7}$

Denoting by $H_{i, t}$ the habit stock inherited from past consumption behavior, and designating total resources available for consumption (the sum of undepreciated past capital, current capital income, and current labor income) as $X_{i, t}$, the consumer's optimization problem for a finite horizon beginning at the current period $t$ and ending at period $T$ (and dropping the $i$ subscripts to reduce clutter) is given by

$$
\begin{aligned}
V_{t}\left(X_{t}, P_{t}, H_{t}\right) & =\max _{\left\{C_{s}\right\}_{t}^{T}} u\left(C_{t}, H_{t}\right)+E_{t}\left[\sum_{s=t+1}^{T} \beta^{s-t} u\left(\tilde{C}_{s}, \tilde{H}_{s}\right)\right] \\
\text { s.t. } & \\
K_{t} & =X_{t}-C_{t}, \\
H_{t+1} & =H_{t}+\lambda\left(C_{t}-H_{t}\right), \\
X_{t+1} & =R K_{t}+Y_{t+1}, \\
Y_{t+1} & =P_{t+1} \epsilon_{t+1}, \\
P_{t+1} & =G_{t+1} P_{t} N_{t+1},
\end{aligned}
$$

where $K_{t}$ is the proportion of total available resources from the beginning of the period $X_{t}$ that have not been consumed at the end of the period. Habits as of the beginning of next period $H_{t+1}$ will have moved from where they started out in this period $\left(H_{t}\right)$ toward this period's consumption. Next period's total resources $X_{t+1}$ will equal the return $R=(1+r)$ (net of depreciation) on this period's end-of-period capital, plus labor income $Y_{t+1}$. Labor income will equal permanent labor income $P_{t+1}$ multiplied by the transitory shock $\epsilon_{t+1}$, and permanent labor income next period will equal permanent labor income this period increased by the gross labor productivity growth factor $G=(1+g)$ and multiplied by a stochastic shock to permanent income $N_{t+1}$ with mean one. As usual, the recursive nature of the problem allows us to rewrite the maximand as:

$$
V_{t}\left(X_{t}, P_{t}, H_{t}\right)=\max _{\left\{C_{t}\right\}} u\left(C_{t}, H_{t}\right)+\beta E_{t}\left[V_{t+1}\left(\tilde{X}_{t+1}, \tilde{P}_{t+1}, H_{t+1}\right)\right] .
$$

Following C-O-W the utility function is of the form

$$
u\left(C_{t}, H_{t}\right)=\frac{\left(C_{t} / H_{t}^{\gamma}\right)^{1-\rho}}{1-\rho} .
$$

This form has several appealing characteristics as a way to model habits. The first is its intuitive structure: Fuhrer (2000) and Carroll, Overland, and Weil (2000) show that in the steady-state of the nonstochastic model, the quantity which yields utility by being raised to the $(1-\rho)$ power becomes

$$
C H^{-\gamma}=C^{1-\gamma}(1+g / \lambda)^{\gamma}
$$

${ }^{7}$ Note that the assumption that $N$ is lognormally distributed and that $E[\tilde{N}]=1$ imply that $\log N \sim$ $\mathcal{N}\left(-\sigma_{N}^{2} / 2, \sigma_{N}^{2}\right)$, i.e. $N$ is $\operatorname{lognormally}$ distributed and $\log N$ has variance $\sigma_{N}^{2}$ and mean $-\sigma_{N}^{2} / 2$. 
where $g$ is the steady-state growth rate of consumption. Thus, utility is derived from a geometric mean of the level and the (scaled) growth rate of consumption, and the parameter $\gamma$ allows us to 'tune' the importance of habits in utility. If $\gamma=0$ then only the absolute level of consumption is important (the standard CRRA model), while if $\gamma=1$, then consumption relative to the habit stock (i.e., growth) is all that matters. For the feasible values of $\gamma$ between zero and one, both the absolute and the relative levels are important. For example, if $\gamma=.5$, then a person with consumption of 2 and habit stock of 1 would have the same utility as a person with both consumption and habit stock equal to 4 . Finally, we assume that $\rho>\frac{1}{1-\gamma}$, a technical condition required for the solution to be well behaved.

Another important feature of this specification, particularly for a model with substantial microeconomic uncertainty, is that so long as consumption remains positive, the utility function remains finite and well-defined. This is in contrast with 'subtractive' utility functions of the form $u(C, H)=(C-\gamma H)^{1-\rho} /(1-\rho)$ used, for example, by Constantinides (1990). In such models, if $\gamma$ is substantially greater than zero then microeconomically plausible amounts of variation in consumption can lead to negative values for $(C-\gamma H)$ and therefore to nonsensical values for utility. ${ }^{8}$

The model as written has three continuously-valued state variables, $X_{t}, H_{t}$, and $P_{t}$. Given the computational challenges of solving models with three state variables, it behooves us to consider whether the dimensionality of the problem can somehow be reduced. It turns out that it can: the model can be recast by dividing all stock and flow variables by the level of permanent income, and then becomes a problem in two state variables and permanent income becomes simply a scaling term. Specifically, define $x_{t}=X_{t} / P_{t}, c_{t}=C_{t} / P_{t}$, and so on. The accumulation equation for $x_{t}$ is

$$
\begin{aligned}
X_{t+1} & =R\left[X_{t}-C_{t}\right]+Y_{t+1} \\
x_{t+1} P_{t+1} & =R P_{t}\left[x_{t}-c_{t}\right]+P_{t+1} \epsilon_{t+1} \\
x_{t+1} & =\left(R / G_{t+1} N_{t+1}\right)\left[x_{t}-c_{t}\right]+\epsilon_{t+1}
\end{aligned}
$$

and the equation for $h_{t+1}$ is

$$
\begin{aligned}
H_{t+1} & =H_{t}+\lambda\left(C_{t}-H_{t}\right) \\
h_{t+1} P_{t+1} & =h_{t} P_{t}+\lambda\left(c_{t} P_{t}-h_{t} P_{t}\right) \\
h_{t+1} G_{t+1} N_{t+1} P_{t} & =P_{t}\left(h_{t}+\lambda\left(c_{t}-h_{t}\right)\right) \\
h_{t+1} & =\frac{h_{t}+\lambda\left(c_{t}-h_{t}\right)}{G_{t+1} N_{t+1}} .
\end{aligned}
$$

The appendix contains details of the demonstration that the problem can be renor-

\footnotetext{
${ }^{8}$ Campbell and Cochrane (1999) use the subtractive formulation, but assume that the accumulation equation for $h$ takes a nonlinear form that causes $h$ to fall as $c$ gets closer and closer to $h$, preventing $c$ from ever falling below $h$. Aside from its role in averting negative values of $c-h$, however, the effects and meaning of this nonlinear accumulation equation are difficult to understand.
} 
malized; the conclusion is that if we solve the problem

$$
\begin{aligned}
v_{t}\left(x_{t}, h_{t}\right) & =\max _{\{c t\}} u\left(c_{t}, h_{t}\right)+\beta E_{t}\left[\left(\tilde{G}_{t+1} \tilde{N}_{t+1}\right)^{(1-\gamma)(1-\rho)} v_{t+1}\left(\tilde{x}_{t+1}, \tilde{h}_{t}\right)\right] \\
\text { s.t. } & \\
x_{t+1} & =\left(R / G_{t+1} N_{t+1}\right)\left[x_{t}-c_{t}\right]+\epsilon_{t+1} \\
h_{t+1} & =\frac{(1-\lambda) h_{t}+\lambda c_{t}}{G_{t+1} N_{t+1}} .
\end{aligned}
$$

for the policy rules $c_{t}\left(x_{t}, h_{t}\right)$, then the optimal policy rules for the level of consumption will be given by $C_{t}\left(X_{t}, H_{t}, P_{t}\right)=c_{t}\left(X_{t} / P_{t}, H_{t} / P_{t}\right) P_{t}$.

The methods in Carroll (1996) can be extended to this case to prove that the successive rules will converge if the 'impatience' condition

$$
R \beta E_{t}\left[\left(\tilde{G}_{t+1} \tilde{N}_{t+1}\right)^{-\hat{\rho}}\right]<1
$$

holds, where $\hat{\rho}=\rho+\gamma(1-\rho)$ and this condition corresponds to a requirement that consumers are sufficiently impatient that as wealth approaches infinity eventually a point arrives at which they would wish to consume more than their current labor and capital income. ${ }^{9}$ Details of the solution method can be found in the appendix.

\section{Parameterization}

This section begins by parameterizing the baseline version of the model with intertemporally separable utility, then considers parameterizing the habit formation version of the model.

I choose conventional assumptions for the time preference rate $\beta=.97$ and net interest rate $R=1.03$, where the time period of the model is interpreted as a year. The depreciation rate is taken from Hayashi (1997), who reports (p. 298) that the average depreciation rate in Japan over the past 40 years has been about $\delta=.09$. The baseline coefficient of relative risk aversion will be $\rho=3$, in the middle of the range from 1 to 5 traditionally considered plausible. Finally, Carroll (1992) and several other studies find that the household labor income process in the United States is relatively well-characterized by a distribution with three components. With some small probability $p$, household income is equal to zero (i.e., with probability $p, \epsilon=0$ - these events in the data occur chiefly during unemployment spells); when household income is not equal to zero, $\epsilon$ is distributed lognormally with $\sigma_{\epsilon}^{2}=0.10$; and $N$ is lognormally distributed with standard deviation $\sigma_{N}=0.10$; in the absence of corresponding empirical results for Japan we use the US numbers for $\sigma_{\epsilon}^{2}$ and $\sigma_{N}^{2}$. The unemployment rate in Japan has typically ranged from 2-4 percent over most of the postwar period. Accordingly the probability of an unemployment

\footnotetext{
${ }^{9}$ This is the counterpart to the impatience condition derived in Deaton (1991) for the model with liquidity constraints and in Carroll (1996) in the unconstrained case.
} 
spell in which $Y=0$ is set at $p=0.02$ or two percent. ${ }^{10}$

Recent work by Fuhrer (2000) provides some evidence about how to parameterize the habit formation component of the model. Fuhrer estimates a perfect foresight version of the C-O-W model on quarterly U.S. data and obtains a fairly tight parameter estimate of $\gamma=0.8$ for the parameter that indexes the importance of habits in utility. We follow Fuhrer and set $\gamma=0.8 .^{11}$

For the purposes of this paper, the baseline habit formation model is parameterized in such a way as to keep the infinite-horizon coefficient of relative risk aversion equal to the plausible value of three specified in the baseline model with intertemporally separable utility. As C-O-W show, the infinite-horizon coefficient of relative risk aversion in this model is equal to $(\rho+\gamma(1-\rho))$. To make this quantity equal to 3 given that $\gamma=0.8$ as estimated by Fuhrer, it is necessary to assume an instantaneous coefficient of relative risk aversion of $\rho=11 .{ }^{12}$

The final parametric choice is for the speed at which habits catch up to consumption, $\lambda$. The baseline value is $\lambda=0.2$, the value used in $\mathrm{C}-\mathrm{O}-\mathrm{W}$ for most of their analysis. This value implies that the half-life with which habits move toward consumption is about three years (because $(1-.2)^{3}=.512 \approx 1 / 2$ ). After presenting the results under these baseline parameter values we will explore sensitivity of our results to this and our other parametric assumptions.

\section{Saving and Growth Redux}

As a preliminary experiment with the model, we need to reexamine the question that motivated the original work in $\mathrm{C}-\mathrm{O}-\mathrm{W}$ : is the apparent fact that growth causes saving consistent with the baseline model without habits, and if not does adding habits help?

Before attempting to answer this question we must specify the stochastic process governing growth in this economy. Roughly speaking, the postwar history of growth in Japan falls into three periods. The first of these was the period of astonishingly rapid growth from the late 1940s to the mid 1970s, which far exceeded the growth experience

\footnotetext{
${ }^{10} \mathrm{~A}$ number less than the observed unemployment rate was chosen because the spells in this model are assumed to last for a full year and there are no unemployment benefits or other social insurance mechanisms. Since both of these assumptions are probably too strong, we compensate by choosing a low value of $p$.

${ }^{11}$ Oddly, when the same model is estimated on a set of several countries in Fuhrer and Klein (1998), Japan is the only country in which the model with habits is not statistically different from the standard model without habits. However, the Fuhrer and Klein paper uses high frequency variation in the data to identify the structural relationships, and many aspects of Japanese NIPA data appear to have strange properties at high frequencies. For example, Campbell and Mankiw (1991) find that Japan is the only country in which income growth is so unpredictable that their consumption model cannot even be estimated. In any case, the Fuhrer and Klein paper does not provide point estimates for $\gamma$ and $\lambda$ for Japan, so is simply not possible to use their results to parameterize this paper's model.

${ }^{12}$ Such a high value for the instantaneous coefficient of relative risk aversion may seem implausible; however, this is essentially the mechanism that allows models with habits to explain the equity premium. Thus rejecting an instantaneous value of $\rho=11$ is equivalent to rejecting the habit formation explanation of the equity premium puzzle. See Campbell and Cochrane (1999) for more discussion of this issue.
} 
of any other country in any previous era of human history. The second was the period beginning in the early 1970s and ending in the late 1980s when Japan still managed to achieve an impressive growth rate but not one that was radically higher than the growth achieved in other industrialized countries. The third era is of course the decade of the 1990s when Japan's growth has been dismal. In none of these three cases can a compelling case be made that the change in 'growth regime' was widely anticipated in advance. The simplest model that seems to capture this pattern of experience is a first-order Markov transition process for the underlying level of the growth process. For simplicity of analysis, I will assume a two-state rather than a three-state Markov process that switches between $G^{L}=1.02$ during the Low growth state and $G^{H}=1.06$ during the High growth state with transition matrix

\begin{tabular}{|c|c|c|}
\hline & $G_{t+1}^{L}$ & $G_{t+1}^{H}$ \\
\hline$G_{t}^{L}$ & $1-(1 / 30)$ & $1 / 30$ \\
$G_{t}^{H}$ & $1 / 30$ & $1-(1 / 30)$ \\
\hline
\end{tabular}

where the transition probabilities are chosen so that the expected duration of the high and low growth periods is 30 years, which roughly corresponds to the length of time Japan stayed in the high-growth regime (mid-40's to mid-70's). In concord with this baseline transition matrix, our simulation results will track an economy over a 90 year period that consists of a 30-year-long period of slow growth followed by a 30-year-long period of fast growth followed by a switch back to the low-growth state for the final 30 periods.

Having specified the actual growth process, we now turn to the question of how consumers perceive that growth process. It turns out that the effect of growth on saving depends quite importantly on consumers' expectations, and the appropriate assumption to make is not at all clear. On the one hand, surely nobody in Japan (or anywhere else for that matter) knew in the late 1940s that the country had just embarked on what would turn out to be the most impressive and sustained period of economic growth that the world had ever seen, in any country, in any era. On the other hand, once Japan had been growing at this remarkable pace for, say, twenty years, it seems probable that the twenty-first year of rapid growth did not come as a complete surprise. Similar considerations apply with respect to the period of very slow growth since 1989: presumably nobody knew in 1989 what a dismal decade the 1990s would be. But after the poor performance of the period through 1998, slow growth in 1999 was hardly a shock.

A potentially plausible formal model of households' perceptions about the income process would be one in which households engage in Bayesian updating with respect to their beliefs about which state the economy is in and about the values in the transition matrices. However, such an exercise would greatly increase the already formidable difficulty of solving the model, because it would be necessary for consumers to forecast their own future forecasts and their own future forecasts of future forecasts, and so on. Instead, we present two sets of results, each of which corresponds to one of the extreme possibilities: either consumers always have perfect knowledge of the current state of the economy and the transition probabilities (consumers are 'smart') or they attach equal probability at 
all times to the probability that the economy is in each of the two states (consumers are 'dumb') and thus they always forecast growth to be equal to the mean of growth in the low state and growth in the high state. Presumably, the truth lies somewhere in between, and presumably the results that would emerge from the Bayesian updating model would also lie between the results that emerge from the two extreme cases presented here.

A last detail is how we specify the initial state of our economy at the beginning of the simulations. The usual procedure is simply to simulate the model for a long 'presample' period and then to begin monitoring it at the beginning of the period that is defined as the 'sample' period. Our procedure yields similar results but is more efficient: in the first period of 'life' of our economy we endow all of the consumers in our model with a stock of cash-on-hand and a habit stock equal to the 'target' values that are implied by their consumption rules and their expectations. Specifically, the target value $x^{*}$ for $x_{t}$ is defined as the value of $x$ such that $E_{t}\left[\tilde{x}_{t+1}\right]=x_{t}$, and similarly $h^{*}$ is the value of $h_{t}$ such that $E_{t}\left[\tilde{h}_{t+1}\right]=h_{t}$. Actually, it is necessary to define $x^{*}$ and $h^{*}$ jointly, because the value of each variable affects the value of the other. Thus

$$
\begin{aligned}
x_{t+1} & =\left(R / G_{t+1} N_{t+1}\right)\left(x_{t}-c_{t}\right)+\epsilon_{t+1} \\
E_{t}\left[\tilde{x}_{t+1}\right] & =E_{t}\left[R / \tilde{G}_{t+1}\right] \exp \left[\sigma_{N}^{2}\right]\left(x_{t}-c_{t}\right)+1 \\
x^{*} & =E_{t}\left[R / \tilde{G}_{t+1}\right] \exp \left[\sigma_{N}^{2}\right]\left(x^{*}-c\left(x^{*}, h^{*}\right)\right)+1
\end{aligned}
$$

where we use the fact that if $\log N \sim \mathcal{N}\left(-\sigma_{N}^{2} / 2, \sigma_{N}^{2}\right)$ then $E[(1 / N)]=\exp \left[\sigma_{N}^{2}\right]$. We also can write

$$
\begin{aligned}
h_{t+1} & =\frac{h_{t}+\lambda\left(c_{t}-h_{t}\right)}{G_{t+1} N_{t+1}} \\
E_{t}\left[\tilde{h}_{t+1}\right] & =E_{t}\left[\frac{(1-\lambda) h_{t}+\lambda c_{t}}{\tilde{G}_{t+1} \tilde{N}_{t+1}}\right] \\
h^{*} & =\left((1-\lambda) h^{*}+\lambda c\left(x^{*}, h^{*}\right)\right) \exp \left[\sigma_{N}^{2}\right] E_{t}\left[1 / \tilde{G}_{t+1}\right] .
\end{aligned}
$$

and the target values of $x^{*}$ and $h^{*}$ are those values that satisfy equations (12) and (13) simultaneously.

\subsection{Dumb Consumers}

As will be evident shortly, the actual average amount of wealth held by consumers in this economy tends to be fairly close to the target stocks defined by equations (12) and (13). ${ }^{13}$ This is convenient because it allows us to use the expressions for the targets to gain insight about the behavior of the aggregates.

For example, consider a consumer in the baseline model (without habits) who happens to hold exactly what he perceives to be his target stock of wealth in period $t, x_{t}=x^{*}$. But recall that the 'target' wealth is defined with respect to the expectation about the growth

\footnotetext{
${ }^{13}$ This is unsurprising, but remember that because the decision rules are nonlinear, in principle the average and 'target' values of $x_{t}$ and $h_{t}$ need not be close.
} 


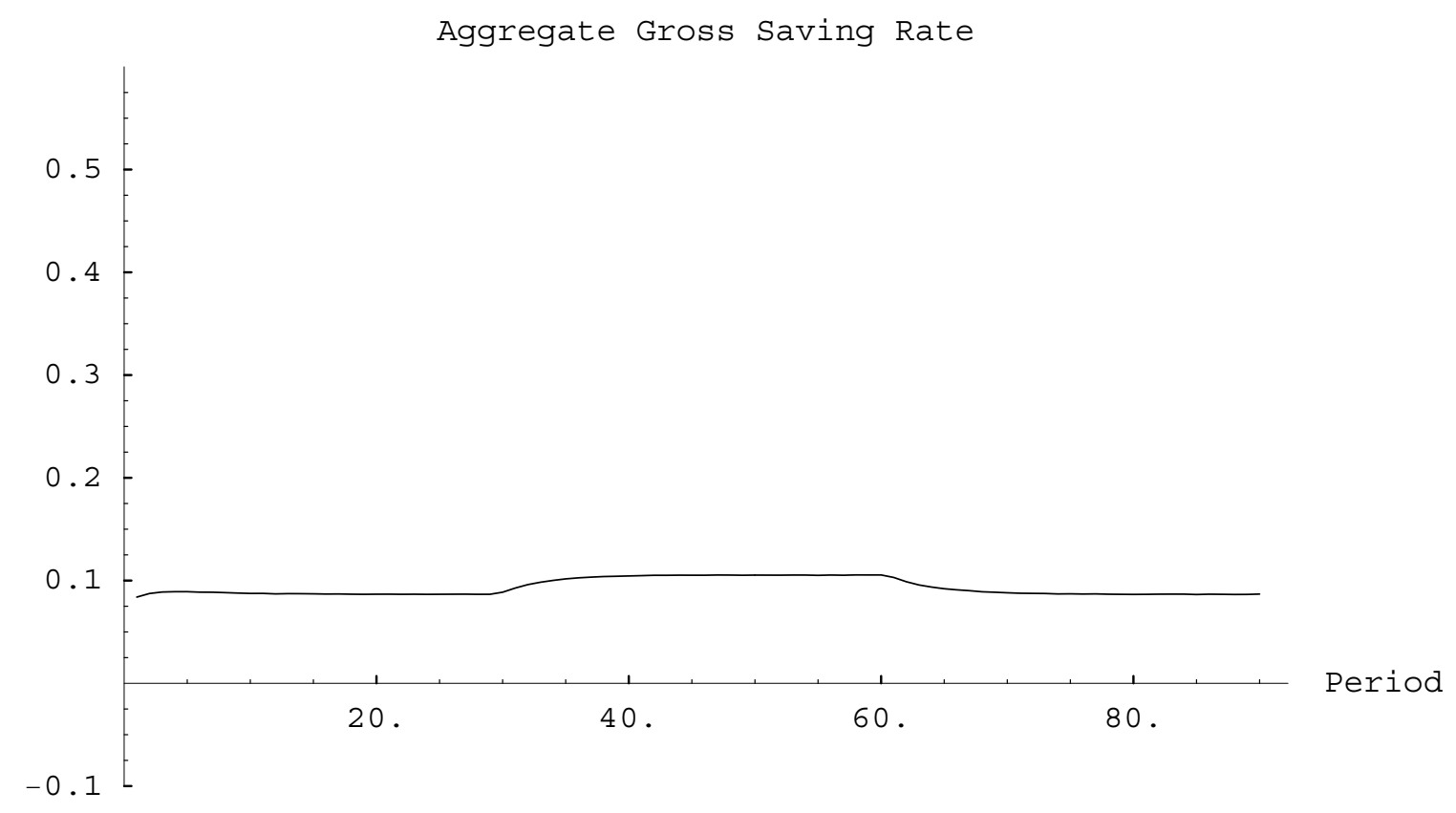

Figure 1: Dumb Consumers, No Habits

rate of permanent income $G$, which dumb consumers perceive to be given by $\operatorname{Pr}\left(G_{t+1}=\right.$ $\left.G^{H}\right)=\operatorname{Pr}\left(G_{t+1}=G^{L}\right)=.5$. Recall also that the accumulation equation is $x_{t+1}=$ $\left(R / G_{t+1} N_{t+1}\right) s_{t}+\epsilon_{t+1}$. When the economy is in the 'high' state, the true mathematical expectation of $E_{t}\left[1 / G_{t+1} \mid\right.$ Truth $]<E_{t}\left[1 / G_{t+1} \mid\right.$ Dumb $]$. It follows that $E_{t}\left[\tilde{x}_{t+1} \mid\right.$ Truth $]<$ $E_{t}\left[\tilde{x}_{t+1} \mid \mathrm{Dumb}\right]=x^{*}$. That is, because $G_{t+1}$ is greater than anticipated, $x_{t+1}$ will be lower than anticipated. We will call this story henceforth the ' $G$ shrinks $x$ ' effect.

What can we conclude about the saving rate on the basis of the ' $G$ shrinks $x$ ' effect? We know from Carroll and Kimball (1996) that the consumption function for this problem is strictly concave with a slope greater than the slope in the perfect foresight case, which implies that reducing $x_{t}$ will reduce consumption by more than the reduction in interest earnings. That is, the lower level of $x_{t}$ boosts the precautionary saving motive and thus the saving rate increases. The converse logic holds when the economy is in the slow-growth regime. Hence for the economy with dumb consumers the ' $G$ shrinks $x$ ' effect implies that the saving rate should rise when the economy switches to the high-growth regime and should fall in the slow-growth regime. The size of these effects can be determined only by simulation.

Figure 1 presents the results when we initialize a population of 5000 agents with the target value of $x^{*}$ in period 1 and identical inital values of permanent income normalized to one (i.e. $\left\{x_{i, 1}, P_{i, 1}\right\}=\left\{x^{*}, 1\right\} \forall i$ ), and then simulate the 90 year sequence described above. The first point evident from the figure is that there is little movement in the aggregate saving rate from the first period to the thirtieth period, confirming the earlier claim that initializing the population such that everybody holds the target value of wealth generates 
aggregate results very similar to those obtained by starting at an arbitrary point and simulating until the population has reached something close to the ergodic distribution. ${ }^{14}$

The first substantive conclusion is thus that the ' $G$ shrinks $x$ ' effect is virtually negligible: While the saving rate is indeed higher in the fast-growth than in the slow-growth regime, the difference in saving rates is so small that it is difficult to detect.

Now consider the theory for what we should expect to see in the habit-forming economy. The ' $G$ shrinks $x$ ' effect continues to hold in this model, so we can continue to expect a modest boost to the saving rate from this effect. However, there is another effect in the model with habits. Recall that habits evolve according to

$$
h_{t+1}=\frac{h_{t}+\lambda\left(c_{t}-h_{t}\right)}{G N_{t+1}} .
$$

Note that exactly the same logic holds with respect to the habits-to-permanent-income ratio $h_{t}$ in this equation as held for the wealth-to-permanent-income ratio in the ' $G$ shrinks $x$ ' effect: faster growth will shrink the habits ratio. Furthermore, the effect of a lower level of $h_{t}$ on $c_{t}$ is similar to that of lower $x_{t}$ : lower habits 'drag down' consumption and thereby boost the saving rate. We will call this the ' $G$ shrinks $h$ ' effect.

The simulation results for the economy with dumb habit-forming consumers (where again all 5000 consumers are initialized in period 1 with $\left.\left\{x_{i, 1}, h_{i, 1}, P_{i, 1}\right\}=\left\{x^{*}, h^{*}, 1\right\}\right)$ are depicted in figure 2. In contrast to the results for the dumb non-habit-formers, in Figure 2 the increase in the saving rate during the fast-growth regime is huge. Thus the ' $G$ shrinks $h$ ' effect is apparently quantitatively much more important than the ' $G$ shrinks $x$ ' effect, and as a result the saving rate increases steadily in the wake of the increase in growth.

\subsection{Smart Consumers}

Before examining the results that obtain when consumers are 'smart', another theoretical excursion will be helpful. The standard perfect foresight permanent income model of consumption without uncertainty implies that the level of consumption is given by

$$
\begin{aligned}
C_{t} & =\left(1-R^{-1}(R \beta)^{\mathrm{IES}}\right)\left(K_{t}+\frac{P_{t}}{1-G / R}\right) \\
c_{t} & \approx\left(r-\rho^{-1}(r-\theta)\right)\left(k_{t}+\frac{1}{r-g}\right)
\end{aligned}
$$

\footnotetext{
${ }^{14}$ There is a conceptual problem with the model as described thus far: Because there are permanent shocks to income for each consumer in each period and there is no mechanism which causes an individual consumer's permanent income to revert to the economy's sample mean, in principle the variance of the distribution of permanent income across consumers is perpetually increasing as time passes. This problem can be overcome by assuming, a la Blanchard (1985), that consumers face a constant probability of death. If the dying consumers are replaced by consumers with permanent incomes equal to the mean level of permanent income of the deceased, the variance of the cross-sectional distribution of permanent income no longer expands without bound as time passes. If we assume that the new consumers receive 'bequests' in their first period of life equal on average to the wealth of the dying consumers, it turns out that the implications of this more complicated model are numerically very close to those reported in the paper. In order to keep the presentation and discussion of the model as simple as possible, the paper therefore sticks with the version without death.
} 


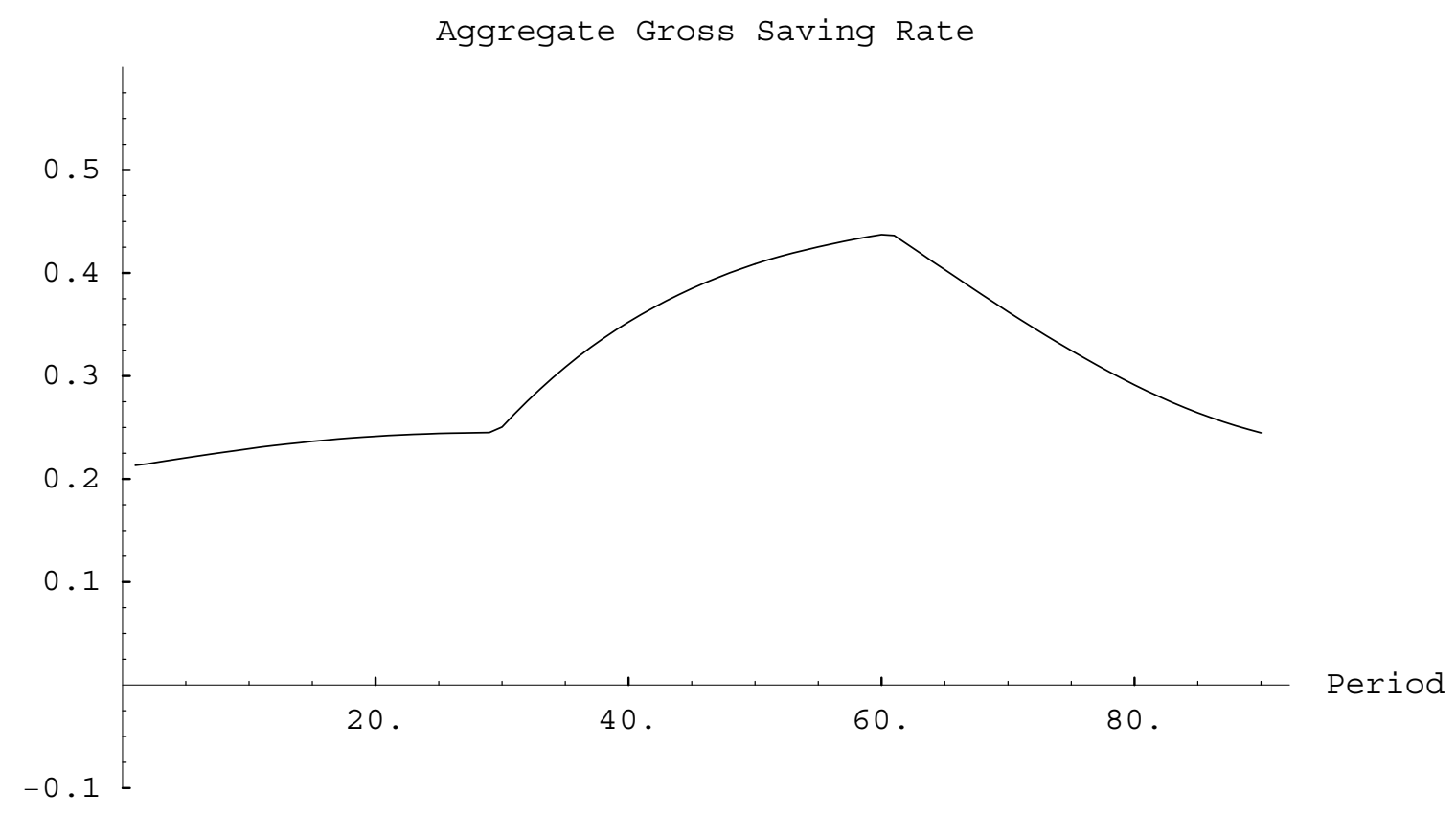

Figure 2: Dumb Consumers, Habits

where IES stands for the intertemporal elasticity of substitution $(1 / \rho), \theta=1 / \beta-1$, and the approximation holds for 'small' $\{r, g, \theta\}$. If we set the aggregate value of $k=4$ and assume a value of $r=.03$ and $g=.01$ it is clear that the elasticity of consumption with respect to the growth rate of income will be colossal. This enormous 'human wealth effect' is a well-known problem with the perfect foresight/certainty equivalent life cycle model of consumption, emphasized, for example, by Tobin (1967), Carroll and Summers (1991), Deaton (1992), and Viard (1993)..$^{15}$

There was no human wealth effect of switching from $G^{L}$ to $G^{H}$ and back in the simulations for dumb consumers, because by definition the 'dumb' consumers' expectations of $G$ did not change when the actual aggregate state changed. However, the human wealth effect will clearly exist for smart consumers who do understand the aggregate growth process. What is not so clear a priori is whether the human wealth effect will be large or small. Carroll (1997) has shown that the introduction of uncertainty can reduce the human wealth effect from enormous to negligible if consumers are assumed to be sufficiently impatient, so we must turn to simulation results to see whether the effect is large or small in this particular context.

Figure 3 shows the time path of the aggregate gross saving rate for an economy populated by smart consumers without habits. The transition to the fast growth regime which

\footnotetext{
${ }^{15}$ Although some papers, notably Horioka and Watanabe (1997) and Horioka (1997), have argued that movements in the Japanese saving rate can be explained by demographic trends, recent work by Deaton and Paxson $(1997,2000)$ finds little support for the proposition that demographic differences can explain cross-country saving differentials, a finding confirmed by Rodrik (1999).
} 


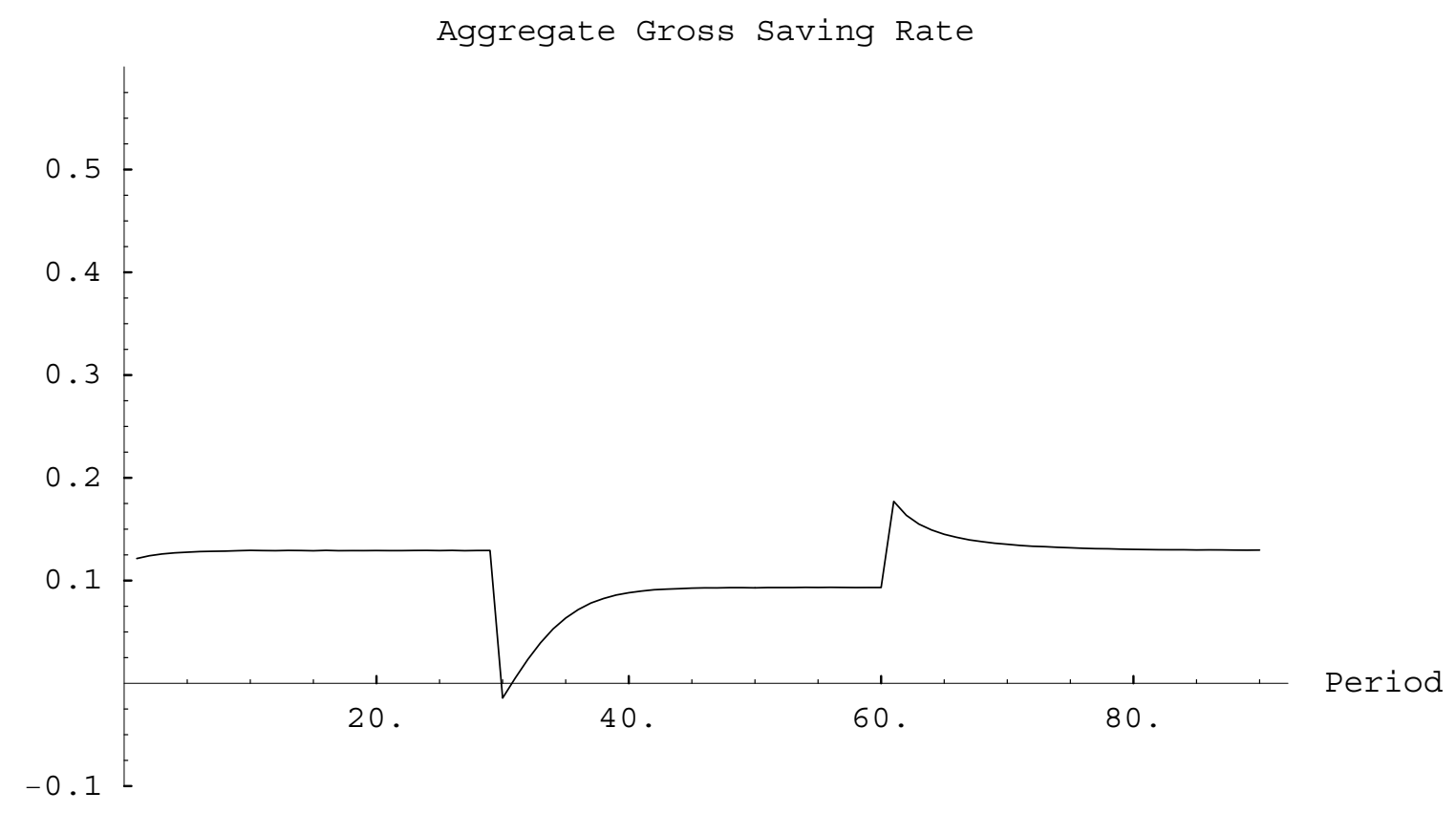

Figure 3: Smart Consumers, No Habits

occurs in period 30 results in a dramatic plunge in the saving rate, indicating that the human wealth effect is quite strong: when consumers learn that they are going to have vastly higher incomes in the future, they go on a spending spree. Over the next twenty years the saving rate gradually climbs back up somewhat, but it never reattains the level that prevailed before the economy shifted to the high-growth regime.

When the economy switches back to the low-growth regime in period 60 , the aggregate saving rate instantly leaps upward, because of a negative human wealth effect: consumers suddenly learn that they will be much poorer in the future than they had thought, so their consumption plummets.

The next figure shows what happens when consumers are again smart but now have habit-forming utility. The intitial drop in the saving rate when the economy switches into the high-growth regime is so small that it is hard to detect - much smaller than the plunge that happened in the non-habit-forming economy. Furthermore, the gross saving rate quickly regains and subsequently exceeds its rate in the low-growth regime.

The logic behind the differences here is somewhat subtle. One's first intuition is that habits must somehow directly reduce the human wealth effect. This turns out to be false. Carroll (2000) shows that in this model of habit formation the formula for consumption in the steady-state of the perfect foresight version of the model is

$$
C_{t}=\left(1-R^{-1}(R \beta)^{\mathrm{IHIES}}\right)\left(K_{t}+\frac{P_{t}}{1-G / R}\right),
$$

where IHIES stands for the Infinite Horizon Intertemporal Elasticity of Substitution. 


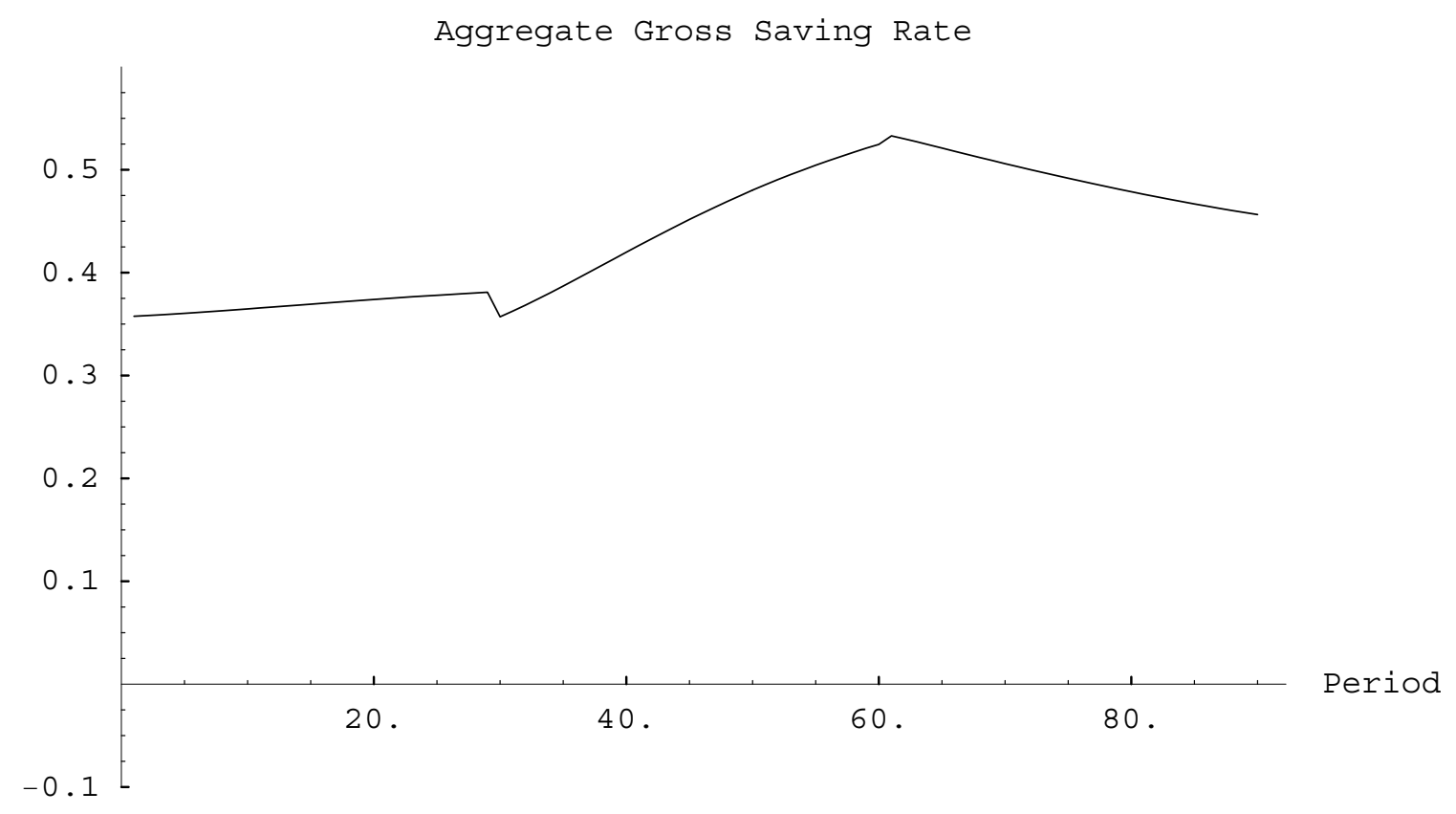

Figure 4: Smart Consumers, Habits

But remember that in parameterizing the habit formation model we chose the parameter values precisely to keep the infinite horizon coefficient of relative risk aversion in the habits model the same as in the baseline model without habits, and since the IHIES is just the inverse of the infinite horizon CRRA, IHIES = IES and therefore the level of steady-state consumption implied by equation (17) is identical to the level of consumption that would occur in the intertemporally separable model, equation (16). Thus, the human wealth effect is exactly as strong in the perfect certainty version of the habit formation model as in the perfect certainty version of the model without habits!

The only possible conclusion is that the differences in outcomes between the two models (and in particular, the ability of the model with habits to explain the positive causality from growth to saving) have to do with the effects of uncertainty on the precautionary saving motive. With a $\gamma$ of 0.8 , it was necessary to assume that $\rho=11$ in order to make the long-term intertemporal elasticity of substitution in the habit formation model match the IES in the baseline model. Thus consumers in this model have an extremely strong aversion to high-frequency fluctuations in consumption and consequently have an extremely strong precautionary saving motive with respect to high frequency risks. As noted earlier, Carroll (1997) shows that the precautionary saving motive can vastly decrease the size of the human wealth effect for impatient consumers, essentially because such consumers are not willing to spend today on the basis of their expected mean level of future income, because of the risk of catastrophically low utility if they fail to save and they experience a bad income shock.

In sum, while the mechanism may be somewhat surprising, these results confirm the 
argument made in $\mathrm{C}-\mathrm{O}-\mathrm{W}$ that habit formation can help explain why the saving rate in East Asian economies seems to have risen systematically in the wake of their take-offs into rapid growth. The effect is stronger if consumers are dumb (in the sense that they did not immediately understand that the economy had switched to a high-growth regime) than if they are smart because the powerful human wealth effect tends to make smart consumers spend more in anticipation of their higher future income. But even for smart consumers, under our baseline parameter values an increase in growth causes a subsequent increase in saving.

\section{The Marginal Propensity to Consume Out of Per- manent Shocks}

We now turn to the question of how habits affect the marginal propensity to consume out of permanent shocks to income (like the permanent tax cut proposed by some analysts of the Japanese economy).

\subsection{Definition}

The first step is to define the MPC out of permanent shocks. This is somewhat less straightforward than one might guess, in part because the timing convention that all uncertainty for period $t$ is resolved at the beginning of the period leads to a minor conceptual difficulty. The level of consumption in period $t+1$ is

$$
P_{t+1} c\left(x_{t+1}, h_{t+1}\right)=G_{t+1} P_{t} N_{t+1} c\left(\left[R / G_{t+1} N_{t+1}\right] k_{t}+\epsilon_{t+1}, \mathcal{H}_{t} / G_{t+1} N_{t+1}\right),
$$

where we define the habit stock at the end of period $t$ as $\mathcal{H}_{t}=h_{t}+\lambda\left(c_{t}-h_{t}\right)$ and the derivative of the expression on the RHS of this equation with respect to the level of the permanent shock $N_{t+1}$ is

$$
\begin{aligned}
{\left[\frac{d C_{t+1}}{d N_{t+1}}\right] } & =\frac{d}{d N_{t+1}} P_{t+1} c\left(x_{t+1}, h_{t+1}\right) \\
& =G_{t+1} P_{t}\left[\frac{d}{d N_{t+1}} N_{t+1} c\left(x_{t+1}, h_{t+1}\right)\right] \\
& =G_{t+1} P_{t}\left[c\left(x_{t+1}, h_{t+1}\right)+N_{t+1}\left(\frac{\partial x_{t+1}}{\partial N_{t+1}} c^{x}\left(x_{t+1}, h_{t+1}\right)+\frac{\partial h_{t+1}}{\partial N_{t+1}} c^{h}\left(x_{t+1}, h_{t+1}\right)\right)\right] .
\end{aligned}
$$

But

$$
\begin{aligned}
& \frac{\partial x_{t+1}}{\partial N_{t+1}}=-\frac{R}{G_{t+1} N_{t+1}^{2}} k_{t} \\
& \frac{\partial h_{t+1}}{\partial N_{t+1}}=-\frac{\mathcal{H}_{t}}{G_{t+1} N_{t+1}^{2}}
\end{aligned}
$$


so, substituting these expressions into (19) we have

$$
\left[\frac{d C_{t+1}}{d N_{t+1}}\right]=G_{t+1} P_{t}\left[c\left(x_{t+1}, h_{t+1}\right)-c^{x}\left(x_{t+1}, h_{t+1}\right) \frac{R}{G_{t+1} N_{t+1}} k_{t}-c^{h}\left(x_{t+1}, h_{t+1}\right) \frac{\mathcal{H}_{t}}{G_{t+1} N_{t+1}}\right]
$$

which depends upon the levels of $G_{t+1}, P_{t}, N_{t+1}, k_{t}, \mathcal{H}_{t}$, and $\epsilon_{t+1}$. But a definition of the marginal propensity to consume as a function in six dimensions would be extremely unwieldy and difficult to analyze - and does not really capture the essence of the concept. Here I use the solution proposed by Carroll (1999) for the problem without habits: First, normalize (19) by the level of permanent income in period $t+1, G_{t+1} P_{t}$, and then define the marginal propensity as the expectation of the scaled version of (19) as of the end of the previous period. This reduces the number of state variables by four, because normalizing eliminates $P_{t}$ and $G_{t+1}$ and taking expectations eliminates $\epsilon_{t+1}$ and $N_{t+1}$.

Thus, we define the 'expected marginal propensity to consume out of permanent shocks to noncapital income' as

$$
\chi\left(k_{t}, \mathcal{H}_{t}\right)=E_{t}\left[c\left(\tilde{x}_{t+1}, \tilde{h}_{t+1}\right)-c^{x}\left(\tilde{x}_{t+1}, \tilde{h}_{t+1}\right) \frac{R}{\tilde{G}_{t+1} \tilde{N}_{t+1}} k_{t}-c^{h}\left(\tilde{x}_{t+1}, \tilde{h}_{t+1}\right) \frac{\mathcal{H}_{t}}{\tilde{G}_{t+1} \tilde{N}_{t+1}}\right]
$$

\subsection{Dumb Consumers, No Habits}

In the version of the model with intertemporally separable utility, habits do not affect utility and so $c^{h}\left(x_{t}, h_{t}\right)=0$, and the formula for the MPC simplifies to

$$
\chi\left(k_{t}, \mathcal{H}_{t}\right)=E_{t}\left[c\left(\tilde{x}_{t+1}, \tilde{h}_{t+1}\right)-c^{x}\left(\tilde{x}_{t+1}, \tilde{h}_{t+1}\right) \frac{R}{\tilde{G}_{t+1} \tilde{N}_{t+1}} k_{t}\right] .
$$

Consider the first term of this expression, $E_{t}\left[c\left(\tilde{x}_{t+1}, \tilde{h}_{t+1}\right)\right]$, for a consumer who happens to be exactly at the target levels of wealth and habits, $k_{t}=k^{*}$, defined as the level of wealth such that $E_{t}\left[\tilde{k}_{t+1}\right]=k_{t}$.

$$
\begin{aligned}
k_{t+1} & =\left(R / G_{t+1} N_{t+1}\right) k_{t}+\epsilon_{t+1}-c\left(x_{t+1}, h_{t+1}\right) \\
E_{t}\left[\tilde{k}_{t+1}\right] & =E_{t}\left[\left(R / \tilde{G}_{t+1} \tilde{N}_{t+1}\right)\right] k_{t}+1-E_{t}\left[c\left(\tilde{x}_{t+1}, \tilde{h}_{t+1}\right)\right] \\
k^{*} & =k^{*} E_{t}\left[\left(R / \tilde{G}_{t+1} \tilde{N}_{t+1}\right)\right]+1-E_{t}\left[c\left(\tilde{x}_{t+1}, \tilde{h}_{t+1}\right)\right] \\
E_{t}\left[c\left(\tilde{x}_{t+1}, \tilde{h}_{t+1}\right)\right] & =1+k^{*}\left[E_{t}\left[\left(R / \tilde{G}_{t+1} \tilde{N}_{t+1}\right)\right]-1\right] \\
E_{t}\left[c\left(\tilde{x}_{t+1}, \tilde{h}_{t+1}\right)\right] & \approx 1+\left(r-\theta-g+\sigma_{N}^{2}\right) k^{*} .
\end{aligned}
$$

where $g=.5\left(G^{H}+G^{L}\right)-1$ and the approximation holds because the baseline values of the parameters $\left\{r, g, \sigma_{N}^{2}\right\}=\{.03, .04, .01\}$ are small.

The principal result in Carroll (1999) is to show that the impatience condition (11), in combination with the results from Carroll and Kimball (1996), implies that for a consumer with the target level of wealth $k_{t}=k^{*}$ the expectation of the second term in $\chi$ is

$$
E_{t}\left[c^{x}\left(\tilde{x}_{t+1}, \tilde{h}_{t+1}\right) \frac{R}{\tilde{G}_{t+1} \tilde{N}_{t+1}} k^{*}\right]>\left(r-\theta-g+\sigma_{N}^{2}\right) k^{*}
$$


and so substituting (24) and (23) into (22) we have $\chi\left(k^{*}, \mathcal{H}\right)<1 \forall \mathcal{H}$. We can gain more insight into this result by realizing that if the parameter values were such that the impatience relationship were exactly on the knife-edge between failing and not failing,

$$
R \beta E_{t}\left[\left(\tilde{G}_{t+1} \tilde{N}_{t+1}\right)^{-\rho}\right]=1
$$

and if there were no precautionary saving motive, we would have $\chi=1$. The insight of Kimball (1990) and Carroll and Kimball (1996) that precautionary saving boosts $c^{x}$ is therefore the effect that allows us to conclude that $\chi<1$. This is an interesting twist, because it says that the reason the marginal propensity to consume out of permanent shocks is less than one is because the marginal propensity to consume out of transitory shocks is boosted by precautionary saving.

The intuition of this is clear: a positive permanent shock reduces $x$, and therefore increases the level of saving out of permanent income, reducing the ratio of consumption to permanent income. This reduction in $c$ means that the level of consumption $C=c P$ does not rise by as much as permanent income $P$, and so the MPC out of the change in $P$ caused by the shock $N$ is less than one.

One further theoretical insight is possible before we turn to the simulation results: we should expect that $\chi$ will be lower during the $G^{H}$ regime than during the $G^{L}$ regime. This follows because the human wealth effect implies that the actual average value of $x_{t}$ will be lower during the $G^{H}$ regime, and Carroll and Kimball (1996) establish that the consumption function is strictly concave for problems of this kind, $c^{x x}<0$, so that the marginal propensity to consume out of transitory shocks $c^{x}$ will be larger with a lower value of $x_{t}$ implying a smaller MPC out of permanent shocks. ${ }^{16}$

Of course, these results tell us nothing about the magnitude of the diminution to $\chi$ caused by the precautionary motive, and so Figure 5 presents the simulation results. It turns out that $\chi$ is around 0.80 in both the $G^{L}$ and the $G^{H}$ regimes, undergoing only a very slight decline when the economy is in the $G^{H}$ regime.

Results in the habit formation model, however, are more interesting. Recall the third term in the habit formation model, $E_{t}\left[-c^{h}\left(\tilde{x}_{t+1}, \tilde{h}_{t+1}\right)\left(\mathcal{H}_{t} / G \tilde{N}_{t+1}\right)\right]$, and remember that $c^{h}$ is positive because consumption tends to be pulled in the direction of habits, so the term as a whole will reduce the marginal propensity to consume as habits pull consumption toward its past average level. Furthermore, our ' $G$ shrinks $h$ ' argument above suggests that $h^{*}$ will be lower in the fast-growing than in the slow-growing economy. However, we have no analytical results for $c^{h h}$ so we do not know whether the contribution of the habit formation term will increase or reduce $\chi$ when the economy switches from slow to fast growth.

Simulation results presented in figure 6 provide the answer: $\chi$ does not change very much across growth regimes. However, the finding of principal interest is that in both the slow-growth and the fast-growth regimes, $\chi$ is a very small number: in either case, the average marginal propensity to consume out of permanent shocks to income is between

\footnotetext{
${ }^{16}$ This logic is loose because the argument is phrased as though there were a stable $c\left(x_{t}, h_{t}\right)$ function across the two regimes, whereas in fact the aggregate state is a state variable and so there will be two different $c\left(x_{t}, h_{t}\right)$ functions, one corresponding to each aggregate state.
} 


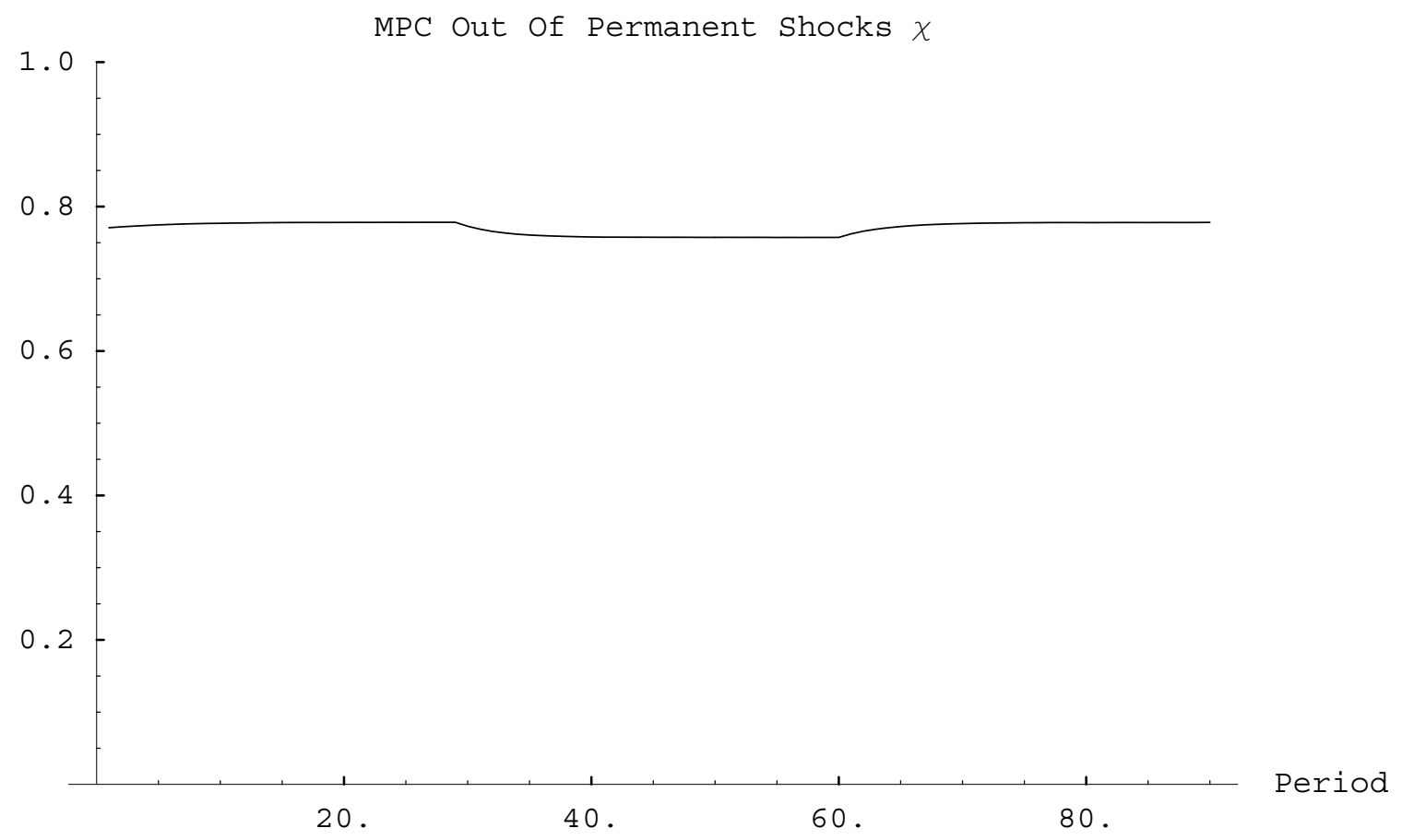

Figure 5: Dumb Consumers, No Habits

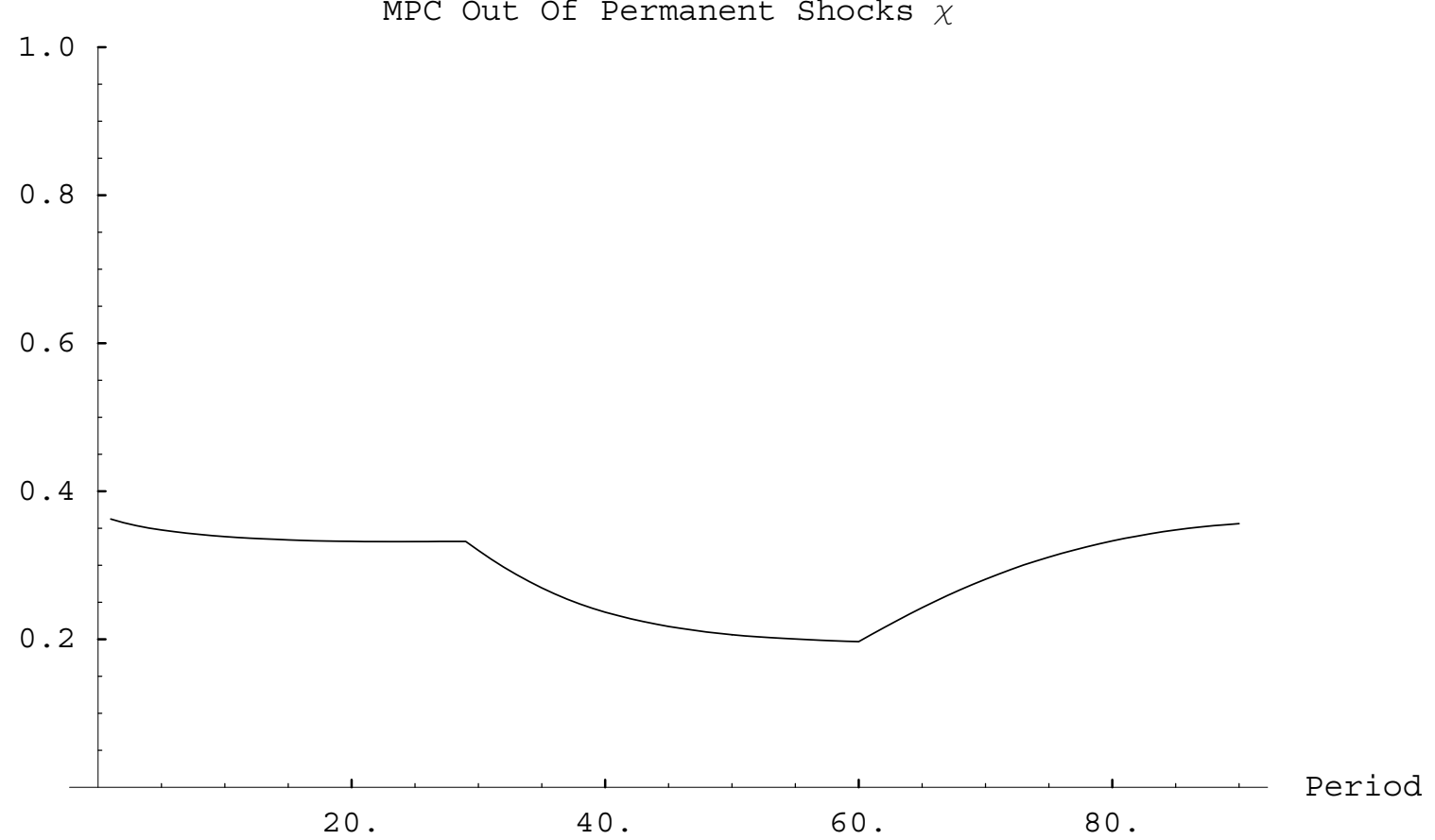

Figure 6: Dumb Consumers, Habits 
about 0.20 and 0.35 . Thus, habits dramatically reduce the marginal propensity to consume out of permanent shocks to income.

\subsection{Smart Consumers}

Earlier we noted that theory suggested, and simulation evidence confirmed, that the human wealth effect would cause a significant difference between the saving behavior of the dumb and the smart consumers across the different growth regimes. What does theory suggest we should expect the human wealth effect to be for smart consumers?

Starting with the consumers with intertemporally separable utility, the sharp reduction in the saving rate in the $G^{H}$ regime leads to a sharp decline in the value of $x^{*}$. But as already noted, Carroll and Kimball (1996) have shown that $c^{x x}<0$ so that loosely speaking we should suspect that a large reduction in $x^{*}$ should correspond to a substantial increase in $c^{x}$, and therefore, by the logic of equation (22) a substantial reduction in $\chi .{ }^{17}$ How large 'substantial' is can be determined only by simulations.

Figure 7 presents results: the steady-state value of $\chi$ in the slow-growth regime is a bit over 0.80 , but when the economy switches to the fast-growth regime the value of $\chi$ heads down toward a new steady-state value of around 0.75 in the $G^{H}$ regime. While the difference between $\chi$ in the low-growth and the high-growth regimes is much larger than in the no-habits economy with dumb consumers depicted in figure 5 , it remains true that the difference between the two regimes is fairly small in terms of policy implications.

Finally, we turn to the results for the economy with smart consumers who have habitforming utility. Once again, there appears to be little that can be said in theoretical terms; the simulation results are in Figure 8. Interestingly, and in contrast with the results for the saving rate, the value of $\chi$ does not change much across the two regimes: the steadystate value is about 0.30 in the low-growth regime and less than 0.20 in the high-growth regime. The important conclusion is that the marginal propensity to consume out of permanent shocks is remarkably small regardless of the growth regime the economy is in. This echoes the results obtained with dumb consumers in figure 6 .

\section{How Long is the Long Run?}

In the long run, consumers must satisfy their intertemporal budget constraints, and so eventually consumption will respond fully to any shock to permanent income. The measure $\chi$ calculated above reflects the first period response only. This section examines how quickly consumption moves most of the way toward permanent income after a permanent shock.

Consider informing the consumer at the end of period $t$ that the process for next period's permanent income shock will be multiplied by $1+\eta$, i.e. the accumulation equation (6) will be replaced (for period $t+1$ only) by

$$
P_{t+1}=G_{t+1} P_{t} N_{t+1}(1+\eta) .
$$

\footnotetext{
${ }^{17}$ Again, the logic is loose; see footnote 16.
} 


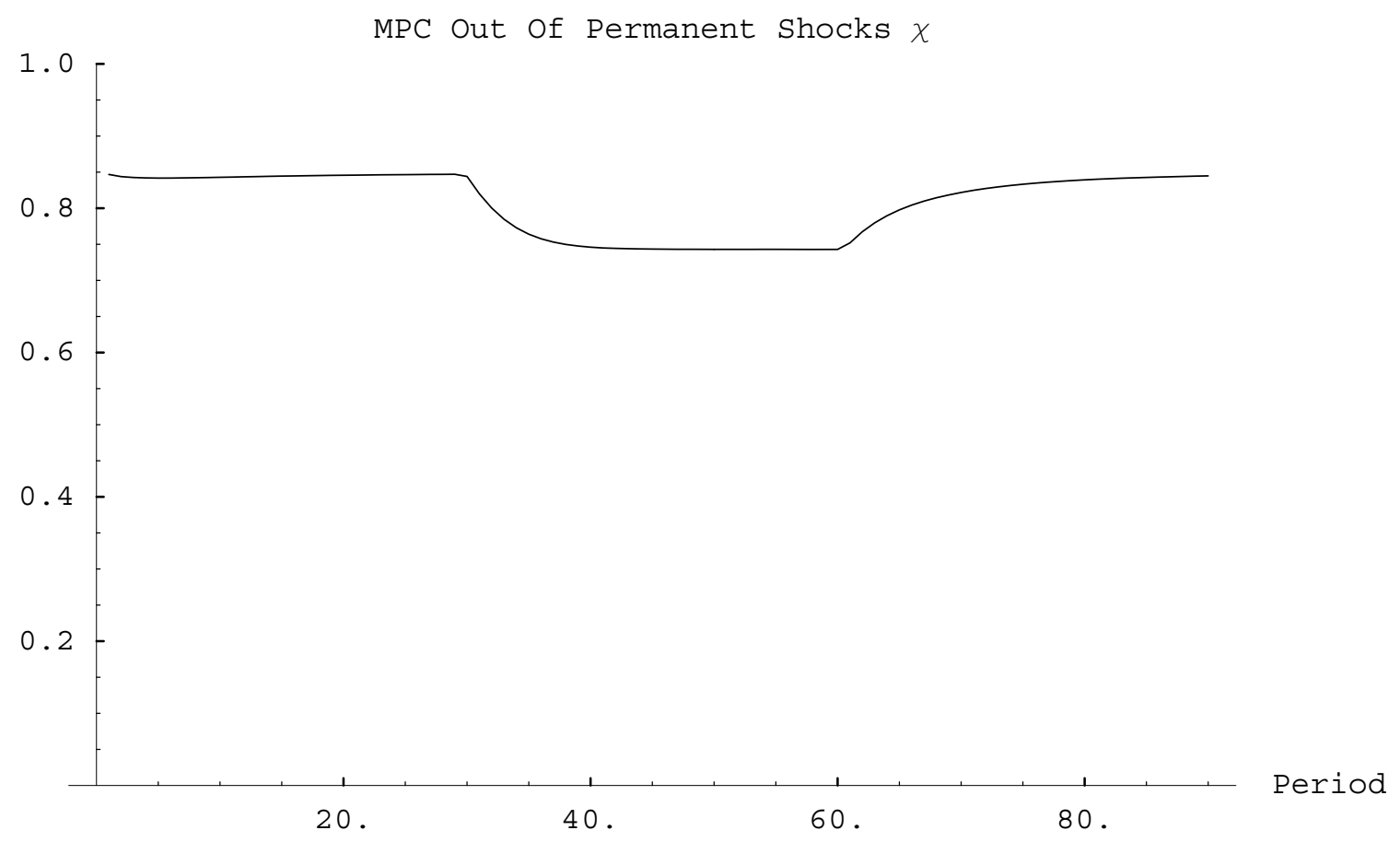

Figure 7: Smart Consumers, No Habits

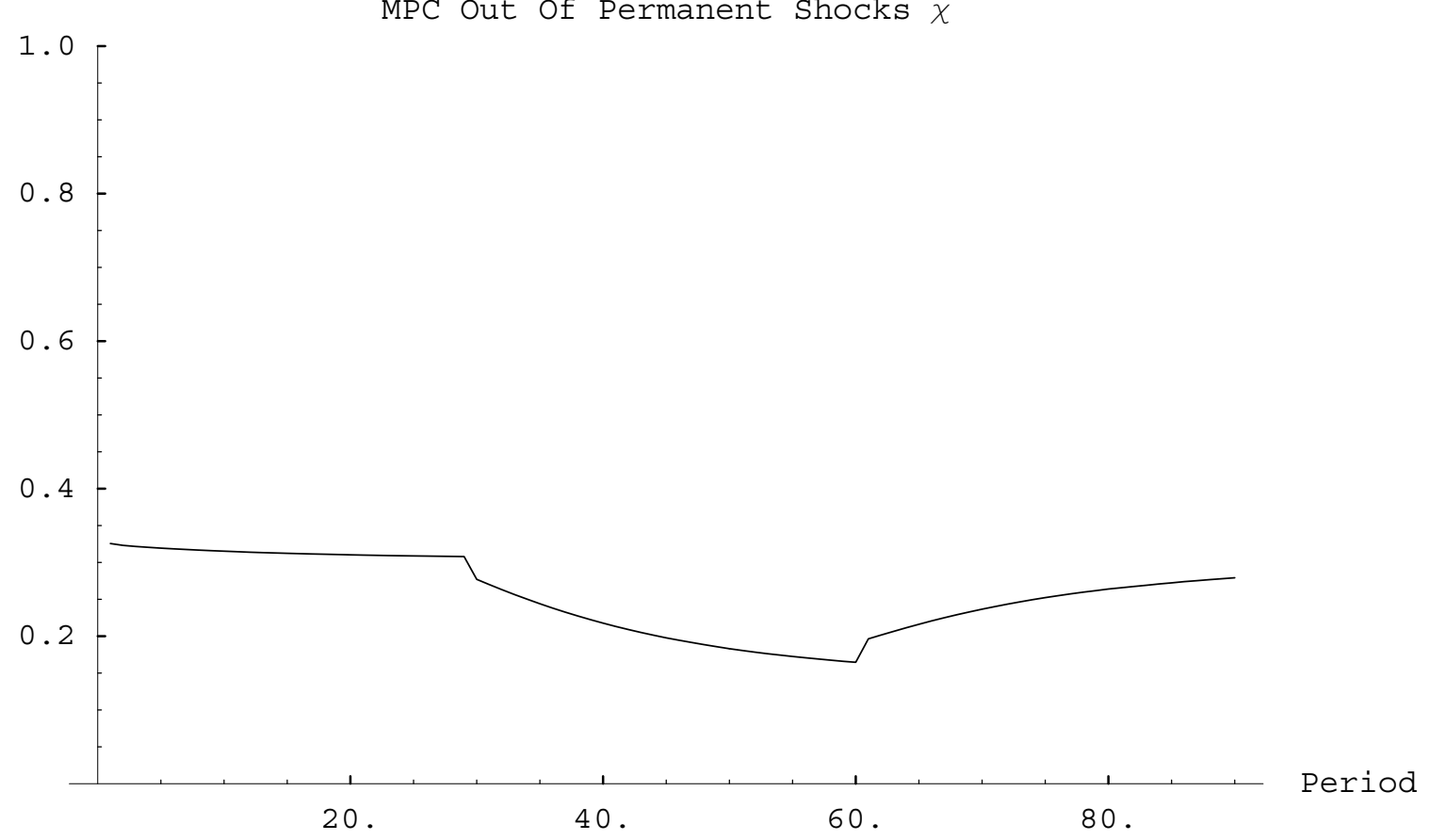

Figure 8: Smart Consumers, Habits 
Now we can define the expected $n$-period marginal propensity to consume out of permanent shock $\eta$ as

$$
\hat{\chi}_{n}\left(k_{t}, \mathcal{H}_{t}, \eta\right)=E_{t}\left[\frac{\tilde{C}_{t+n} / \tilde{\mathcal{G}}_{t, t+n}-C_{t}}{P_{t} \eta}\right],
$$

where $\mathcal{G}_{t, t+n}=G_{t+1} G_{t+2} \ldots G_{t+n} N_{t+1} N_{t+2} \ldots N_{t+n}$. The appendix shows that for $n=1$, for a consumer who in period $t$ is at the target level of consumption $c^{*}$ such that $E_{t}\left[\tilde{c}_{t+1}\right]=$ $c_{t}, \lim _{\eta \rightarrow 0} \hat{\chi}_{1}\left(k_{t}, \mathcal{H}_{t}, \eta\right)=\chi\left(k_{t}, \mathcal{H}_{t}\right)$ as defined above, so $(27)$ is a natural generalization of the one-period MPC.

Because the MPC out of permanent shocks in the model without habits was about 0.80, a natural definition of 'the long run' is the value of $n$ such that $\hat{\chi}_{n}\left(k_{t}, \mathcal{H}_{t}, \eta\right)=0.80$. Thus, the 'long run' corresponds to the length of time it takes before the consumption ratio has adjusted at least 80 percent of the way toward its new steady-state level.

This question would be exceptionally difficult to answer by attempting to calculate the numerical expectation of (27), because of the rapid multiplication of contingencies as the number of periods increases. Fortunately, there is a shortcut. First, rewrite (27) as

$$
\begin{aligned}
\hat{\chi}_{n}\left(k_{t}, \mathcal{H}_{t}, \eta\right) & =E_{t}\left[\frac{\tilde{c}_{t+n} \tilde{P}_{t+n} / \tilde{\mathcal{G}}_{t, t+n}-c_{t} P_{t}}{P_{t} \eta}\right] \\
& =E_{t}\left[\frac{\tilde{c}_{t+n} P_{t}(1+\eta)-c_{t} P_{t}}{P_{t} \eta}\right] \\
& =E_{t}\left[\frac{\tilde{c}_{t+n}(1+\eta)-c_{t}}{\eta}\right] . \\
& =E_{t}\left[\frac{\tilde{c}_{t+n}-c_{t}}{\eta}\right]+E_{t}\left[\tilde{c}_{t+n}\right] .
\end{aligned}
$$

It turns out that in practice the time series process for aggregate $c$ within a growth regime is well approximated by an $\operatorname{AR}(1),{ }^{18}$

$$
E_{t+n}\left[\left(c_{t+n+1}-\bar{c}\right)\right] \approx \mu\left(c_{t+n}-\bar{c}\right)
$$

which means that

$$
\begin{aligned}
\hat{\chi}_{n}\left(k_{t}, \mathcal{H}_{t}, \eta\right) & \approx E_{t}\left[\frac{\mu^{n-1}\left(\tilde{c}_{t+1}-c_{t}\right)}{\eta}\right]+E_{t}\left[\mu^{n-1}\left(\tilde{c}_{t+1}-\bar{c}\right)+\bar{c}\right] \\
& =E_{t}\left[\mu^{n-1}\left(\chi\left(k_{t}, \mathcal{H}_{t}\right)-\tilde{c}_{t+1}\right)\right]+E_{t}\left[\mu^{n-1}\left(\tilde{c}_{t+1}-\bar{c}\right)\right]+\bar{c} \\
& =\mu^{n-1}\left[\chi\left(k_{t}, \mathcal{H}_{t}\right)-\bar{c}\right]+\bar{c}
\end{aligned}
$$

Using the fact that $\hat{\chi}_{1}\left(k_{t}, \mathcal{H}_{t}, \eta\right) \approx \chi\left(k_{t}, \mathcal{H}_{t}\right)$ we can find the $n$ such that $\hat{\chi}_{n}\left(k_{t}, \mathcal{H}_{t}, \eta\right)=$

\footnotetext{
${ }^{18}$ See the appendix for details.
} 
0.8 from

$$
\begin{aligned}
0.8 & \approx \mu^{n-1}\left[\chi\left(k_{t}, \mathcal{H}_{t}\right)-\bar{c}\right]+\bar{c} \\
\log \left[\mu^{n-1}\left[\bar{c}-\chi\left(k_{t}, \mathcal{H}_{t}\right)\right]\right. & \approx \log [\bar{c}-0.8] \\
(n-1) \log \mu+\log \left[\bar{c}-\chi\left(k_{t}, \mathcal{H}_{t}\right)\right] & \approx \log [\bar{c}-0.8] \\
n & \approx 1+\frac{\log [\bar{c}-0.8]-\log \left[\bar{c}-\chi\left(k_{t}, \mathcal{H}_{t}\right)\right]}{\log \mu} .
\end{aligned}
$$

The results are presented in panel A. of Table 6, for dumb and smart consumers who are living in the slow-growth regime. The table shows the average value of $\chi\left(k_{t}, \mathcal{H}_{t}\right)$ along with the estimated value of the $\operatorname{AR}(1)$ coefficient $\mu$ from equation (28) and the standard error for $\mu$. From equation (32), $\mu$ and $\chi$ together imply the speed of adjustment statistic reported in the column labelled 'Years to 0.80.' Also presented for completeness are the $\bar{R}^{2}$ and the Durbin-Watson statistics for the $\mathrm{AR}(1)$ regression; see the appendix for details of the exact procedure for estimating this regression. The first row of the table indicates that under the baseline parameter values, if consumers are dumb aggregate consumption takes about 10 years to adjust 80 percent of the way toward its steady-state value; the second row indicates that if consumers are smart, $\chi$ is virtually unchanged, but it takes a few more years to reach 80 percent adjustment.

\section{Robustness}

This section examines the robustness of the preceding conclusions to alternative assumptions about parameter values. In order to organize the results, it is necessary first to consider the constraints on the possible combinations of parameter values. Recall the 'impatience condition' (11)

$$
E_{t}\left[R \beta\left(\tilde{G}_{t+1} \tilde{N}_{t+1}\right)^{-\hat{\rho}}\right]<1
$$

introduced earlier, where $\hat{\rho}=\rho+\gamma(1-\rho)$. In principle, this condition must be satisfied for the problem to define a contraction mapping and therefore for the solution methods employed here to work. Now consider the case where there is no chance that the aggregate state will change, $G_{t}=G_{t+1} \ldots=G \forall t$, and suppose that the permanent shock is lognormally distributed, $\log N_{t+1} \sim \mathcal{N}\left(-\sigma_{N}^{2} / 2, \sigma_{N}^{2}\right)$. Then (33) becomes

$$
\begin{aligned}
E_{t}\left[R \beta \tilde{N}_{t+1}^{-\hat{\rho}}\right] & <G^{\hat{\rho}} \\
R \beta e^{\hat{\rho} \sigma_{N}^{2} / 2+\hat{\rho}^{2} \sigma_{N}^{2} / 2} & <G^{\hat{\rho}} \\
r-\theta+\hat{\rho}(1+\hat{\rho}) \sigma_{N}^{2} / 2 & <\hat{\rho} g \\
\hat{\rho}^{-1}(r-\theta)+\left(\frac{1+\hat{\rho}}{2}\right) \sigma_{N}^{2} & <g
\end{aligned}
$$

where the transition from (35) to (36) is obtained by taking the logarithm of both sides and holds only approximately. This equation tells us that we cannot consider arbitrary variations in $\rho$ and $\gamma$ - we are restricted to considering variations which satisfy (37). 
Table 1: Results on Speed of Adjustment and Robustness

\begin{tabular}{|c|c|c|c|c|c|}
\hline $\begin{array}{l}\text { Parameter(s) Deviation } \\
\text { from Baseline }\end{array}$ & $\chi\left(k_{t}, \mathcal{H}_{t}\right)$ & $\begin{array}{c}\mathrm{AR}(1) \\
\text { Coeff.(SE) } \\
\end{array}$ & $\begin{array}{c}\text { Years } \\
\text { to } 0.80 \\
\end{array}$ & $\bar{R}^{2}$ & $\begin{array}{l}\text { Durbin } \\
\text { Watson }\end{array}$ \\
\hline \multicolumn{6}{|c|}{ Panel A. Speed of Adjustment for Baseline Parameter Values } \\
\hline Expectations $=$ Dumb & 0.34 & $0.89(0.04)$ & 9.7 & 0.79 & 1.95 \\
\hline Expectations $=$ Smart & 0.31 & $0.93(0.03)$ & 13.7 & 0.87 & 1.97 \\
\hline \multicolumn{6}{|c|}{ Panel B. Sensitivity of Results to $\lambda$} \\
\hline$\lambda=1.0$ & 0.25 & $0.74(0.06)$ & 4.9 & 0.55 & 1.95 \\
\hline$\lambda=0.1$ & 0.34 & $0.95(0.03)$ & 15.7 & 0.90 & 1.97 \\
\hline \multicolumn{6}{|c|}{ Panel C. Sensitivity of Results to $\gamma$ Keeping $\hat{\rho}=3$} \\
\hline$\gamma=0.2, \rho=3.5$ & 0.75 & $0.83(0.05)$ & 2.0 & 0.69 & 2.00 \\
\hline$\gamma=0.5, \rho=5$ & 0.58 & $0.85(0.04)$ & 4.8 & 0.72 & 1.97 \\
\hline \multicolumn{6}{|c|}{ Panel D. Sensitivity of Results to $\rho$ Keeping $\gamma=0.8$} \\
\hline$\rho=6, \hat{\rho}=2$ & 0.37 & $0.91(0.03)$ & 11.1 & 0.83 & 1.97 \\
\hline$\rho=2, \hat{\rho}=1.2$ & 0.50 & $0.84(0.05)$ & 5.7 & 0.70 & 1.94 \\
\hline \multicolumn{6}{|c|}{ Panel E. Sensitivity of Results to $\gamma$ Keeping $\rho=11$} \\
\hline$\gamma=0.85, \hat{\rho}=2$ & 0.27 & $0.94(0.03)$ & 16.7 & 0.89 & 1.97 \\
\hline$\gamma=0.90, \hat{\rho}=4$ & 0.22 & $0.95(0.03)$ & 21.1 & 0.91 & 1.97 \\
\hline \multicolumn{6}{|c|}{ Panel F. Sensitivity of Results to Other Parameters } \\
\hline$\beta=0.96, R=1.04$ & 0.34 & $0.93(0.03)$ & 11.0 & 0.86 & 1.97 \\
\hline$\beta=0.98, R=1.02$ & 0.26 & $0.94(0.03)$ & 17.5 & 0.88 & 1.98 \\
\hline Unemp Prob $=0.01$ & 0.31 & $0.93(0.03)$ & 12.9 & 0.86 & 1.98 \\
\hline Unemp Prob $=0.03$ & 0.30 & $0.94(0.03)$ & 14.5 & 0.87 & 1.99 \\
\hline$\sigma_{N}=0.05$ & 0.36 & $0.88(0.04)$ & 9.2 & 0.77 & 1.95 \\
\hline$\sigma_{N}=0.10$ & 0.35 & $0.90(0.04)$ & 10.3 & 0.80 & 1.95 \\
\hline$\sigma_{\epsilon}=0.05$ & 0.30 & $0.93(0.03)$ & 13.9 & 0.87 & 1.98 \\
\hline$\sigma_{\epsilon}=0.15$ & 0.30 & $0.93(0.03)$ & 13.6 & 0.87 & 1.97 \\
\hline
\end{tabular}

Notes: Baseline assumes smart consumers, $\rho=11, \gamma=0.8$ (jointly implying $\hat{\rho}=3$ ), $\beta=0.97, R=1.03, G=1.02, \sigma_{N}=0.1, \sigma_{\epsilon}=0.1, p=0.02$.

Expectations $=$ Smart for all rows after Panel A. 
Our baseline parameter values for these experiments are as specified above: $\gamma=0.8$ and $\rho=11$ implying $\hat{\rho}=3 ; r=\theta=0.03 ; \sigma_{N}^{2}=0.01$. Note that these parameters imply that

$$
\hat{\rho}^{-1}(r-\theta)+\left(\frac{1+\hat{\rho}}{2}\right) \sigma_{N}^{2}=0.02 .
$$

Thus, for the slow-growth regime value of $g=0.02$ our baseline parameter values might appear to be on the knife edge of failing the impatience condition. However, recall that these consumers do not actually expect $g=0.02$; they believe that there is a modest chance that the economy will switch into the fast-growth regime in which $g=0.06$. Thus, the baseline parameter values do satisfy the impatience condition properly specified to take account of this probability.

This is the place to point out that it is necessary to choose baseline parameter values that are close to failing the impatience condition if we wish for the baseline model without habits to produce sensible predictions for the magnitude of the aggregate capital stock. If consumers are highly impatient, they will decide to maintain a modest buffer stock of only a few weeks' or months' worth of income, and the aggregate capital stock predicted the model will fall far below the true aggregate capital/income ratio of about 3. For the baseline parameter values without habits, the model implies a steady-state ratio of capital to labor income of about 2 (for an economy that remains in the two percent growth regime and has no habit formation), somewhat smaller than the corresponding empirical statistic for the U.S., for which $g=0.02$ is a plausible assumption. For the baseline model with habits, the prediction is for a capital to labor income ratio of a bit less than 5, somewhat more than the corresponding empirical statistic in Japan. This seems a reasonable compromise, since clearly the model cannot match the true empirical capital/income ratio both with and without habits. ${ }^{19}$

We will consider three kinds of experiments with the parameter values: Experiments that leave $\hat{\rho}$ the same but alter the values of $\rho$ and $\gamma$; experiments that fix the value of $\rho$ and experiment with the value of $\gamma$ (leaving $\hat{\rho}$ within the bounds set by (37)); and experiments that fix the value of $\gamma$ and experiment with the value of $\rho$ (again within the range of values permitted by (37)). Because results with smart and dumb consumers are very similar, we present results only for smart consumers.

As Panel B. of the table shows, results are not particularly sensitive to the value of $\lambda$ : for values of $\lambda$ between 0.1 and 1.0, the initial MPC ranges from about 0.25 to about 0.35 . Furthermore, even for the case of very rapid adjustment of the habit stock $(\lambda=1.0)$, the economy still takes about 5 years to reach the 'long run' MPC. These findings echo those of Fuhrer (2000), whose estimate of $\lambda$ was rather imprecise because simulation results were not particularly sensitive to the value of $\lambda$.

\footnotetext{
${ }^{19}$ This difficulty points out the drawback of our small open economy assumption; in a closed economy with a neoclassical production function, the equilibrium capital stocks would be closer to each other. To see why, note that the habitless economy's low capital stock would imply high interest rates which would generate higher saving (compared to the partial equilibrium result here), while the large capital stock in the economy with habits would drive down the rate of return and hence reduce saving.
} 
Panel C. explores the consequences of alternative combinations of $\rho$ and $\gamma$ which leave $\hat{\rho}=3$. The results illustrate that, as one would expect, the less important are habits (the smaller is $\gamma$ ) the closer the results are to the outcome obtained without habits.

Panel D. examines the effect of changing the value of $\rho$ while leaving $\gamma$ fixed at its baseline value of 0.8 . When $\rho=6$ (implying $\hat{\rho}=2$ ), the results are only modestly different from the baseline results: $\chi$ edges up and 'years to 0.8 ' drops to about 11. Even pushing $\rho$ as low as 2 (implying $\hat{\rho}=1.2$ ) only boosts $\chi$ to about 0.50 , though 'years to 0.80 ' drops substantially.

Panel E. leaves $\rho$ fixed at its baseline value of 11 but increases $\gamma \cdot{ }^{20}$ The effect of increasing $\gamma$ from the baseline 0.8 to 0.85 is to cut $\chi$ by about 0.05 , and to increase the 'years to 0.8 ' statistic by about 3 years. Setting $\gamma=0.9$ produces further changes in both statistics of about the same magnitude, indicating that these statistics are roughly linear in $\gamma$ in the neighborhood of $\gamma=0.80$. Thus, again, we see that changes in $\gamma$ are quite powerful in their effects.

Panel F. examines the consequences of changing the other parameters of the model which do not affect the impatience condition. In no case considered is $\chi$ changed from its baseline value by more than 0.05 , and in no case does the 'years to 0.8 ' statistic change by more than about 4 from its baseline value. Hence we can conclude that the results are robust to reasonable changes in these parameters.

\section{Conclusion}

A substantial literature has recently developed arguing that several different aspects of consumption and portfolio behavior can be explained using models in which consumption exhibits important habit formation effects. This paper derives a new implication of those models: that the immediate marginal propensity to consume out of permanent shocks to income should be substantially lower than in the traditional model with intertemporally separable utility.

In particular, if the habit formation explanation proposed by Carroll, Overland, and Weil (2000) for the long-term rise in Japan's saving rate is correct, the implication is that permanent tax cuts might not be nearly as effective in stimulating consumption in the short- to medium-run as would be expected in a traditional permanent income model. If the immediate marginal propensity to consume out of permanent tax cuts is as low as 30 percent, other forms of fiscal stimulus may be much more effective than permanent income tax cuts in stimulating aggregate demand.

\footnotetext{
${ }^{20}$ This panel shows only the effect of increasing $\gamma$ because reductions in $\gamma$ would produce a configuration of parameter values that violate the impatience condition. Panel C. shows the results of reducing $\gamma$ while offsetting the effect on impatience.
} 


\section{A Appendix}

\section{A.1 Normalizing By $P_{t}$}

To see that the consumer's optimization problem can be rewritten in ratio form, consider the problem as of the second-to-last period of life.

$$
\begin{aligned}
V_{T-1}\left(X_{T-1}, H_{T-1}, P_{T-1}\right) \\
=\max _{\left\{C_{T-1}\right\}} \frac{\left(C_{T-1} H_{T-1}^{-\gamma}\right)^{1-\rho}}{1-\rho}+\beta E_{T-1}\left[\frac{\left(\tilde{X}_{T} H_{T}^{-\gamma}\right)^{1-\rho}}{1-\rho}\right] \\
=\max _{\left\{c_{T-1}\right\}} \frac{1}{1-\rho}\left(\left(c_{T-1} P_{T-1}\left[h_{T-1} P_{T-1}\right]^{-\gamma}\right)^{1-\rho}+\beta E_{T-1}\left[\left(\tilde{x}_{T} \tilde{P}_{T}\left[\tilde{h}_{T-1} \tilde{P}_{T}\right]^{-\gamma}\right)^{1-\rho}\right]\right) \\
=\max _{\left\{c_{T-1}\right\}} \frac{1}{1-\rho}\left(\left(c_{T-1} h_{T-1}^{-\gamma} P_{T-1}^{1-\gamma}\right)^{1-\rho}+\beta E_{T-1}\left[\left(\tilde{x}_{T} \tilde{h}_{T-1}^{-\gamma} \tilde{P}_{T}^{1-\gamma}\right)^{1-\rho}\right]\right) \\
=\max _{\left\{c_{T-1}\right\}} \frac{1}{1-\rho}\left(\left(c_{T-1} h_{T-1}^{-\gamma} P_{T-1}^{1-\gamma}\right)^{1-\rho}+\beta E_{T-1}\left[\left(\tilde{x}_{T} \tilde{h}_{T-1}^{-\gamma}\left(P_{T-1} G \tilde{N}_{T}\right)^{1-\gamma}\right)^{1-\rho}\right]\right) \\
=P_{T-1}^{(1-\gamma)(1-\rho)} \max _{\left\{c_{T-1}\right\}} \frac{1}{1-\rho}\left(\left(c_{T-1} h_{T-1}^{-\gamma}\right)^{1-\rho}+\beta E_{T-1}\left[\left(\tilde{x}_{T} \tilde{h}_{T-1}^{-\gamma}\left(G \tilde{N}_{T}\right)^{1-\gamma}\right)^{1-\rho}\right]\right) \\
=P_{T-1}^{(1-\gamma)(1-\rho)}\left(\max _{\left\{c_{T-1}\right\}} u\left(c_{T-1}, h_{T-1}\right)+\beta E_{T-1}\left[\left(G \tilde{N}_{T}\right)^{(1-\gamma)(1-\rho)} v_{T}\left(\tilde{x}_{T}, \tilde{h}_{T-1}\right)\right]\right) .
\end{aligned}
$$

where we define $v_{T}\left(x_{T}, h_{T}\right)=u\left(x_{T}, h_{T}\right)$. Now note that if we define

$$
v_{t}\left(x_{t}, h_{t}\right)=\max _{\left\{c_{t}\right\}} u\left(c_{t}, h_{t}\right)+\beta E_{t}\left[\left(G \tilde{N}_{t+1}\right)^{(1-\gamma)(1-\rho)} v_{t+1}\left(\tilde{x}_{t+1}, \tilde{h}_{t}\right)\right]
$$

such that

$$
\begin{aligned}
x_{t+1} & =\left(R / G N_{t+1}\right)\left[x_{t}-c_{t}\right]+\epsilon_{t+1} \\
h_{t+1} & =\frac{(1-\lambda) h_{t}+\lambda c_{t}}{G N_{t+1}} .
\end{aligned}
$$

then the value function for any period $t<T$ can be rewritten as

$$
V_{t}\left(X_{t}, H_{t}, P_{t}\right)=P_{t}^{(1-\gamma)(1-\rho)} v_{t}\left(X_{t} / P_{t}, H_{t} / P_{t}\right)
$$

and for any $t$ the $c_{t}\left(x_{t}, h_{t}\right)$ which maximizes (A.1), it is easy to show that $C_{t}=c_{t}\left(x_{t}, h_{t}\right) P_{t}$ maximizes $V_{t}\left(X_{t}, H_{t}, P_{t}\right)$.

\section{A.2 End-Of-Period Value $\Omega$}

In analyzing problems of this kind it is often useful to define the value of the program at two points within a period: before and after the control variables have been chosen. To do so however requires that we give names to the state variables at the end of the period that are distinct from their names at the beginning. At the end of the period the 
state variables for this problem are capital $k_{t}=x_{t}-c_{t}$ and $\mathcal{H}_{t}=h_{t}+\lambda\left(c_{t}-h_{t}\right)$, and the end-of-period value function is

$$
\Omega_{t}\left(k_{t}, \mathcal{H}_{t}\right)=E_{t}\left[\left(G \tilde{N}_{t+1}\right)^{(1-\rho)(1-\gamma)} v_{t+1}\left(\left(R / G \tilde{N}_{t+1}\right) k_{t}+\tilde{\epsilon}_{t+1}, \mathcal{H}_{t} / G \tilde{N}_{t+1}\right)\right]
$$

and, denoting the derivative of a function $f$ with respect to an argument $z$ as $f^{z}$ we have

$$
\begin{aligned}
\Omega_{t}^{s}\left(k_{t}, \mathcal{H}_{t}\right) & =E_{t}\left[\left(G \tilde{N}_{t+1}\right)^{\rho \gamma-\rho-\gamma} R v_{t+1}^{x}\right] \\
\Omega_{t}^{h}\left(k_{t}, \mathcal{H}_{t}\right) & =E_{t}\left[\left(G \tilde{N}_{t+1}\right)^{\rho \gamma-\rho-\gamma} v_{t+1}^{h}\right] .
\end{aligned}
$$

Using this definition, the maximization problem becomes simply

$$
v_{t}\left(x_{t}, h_{t}\right)=\max _{\left\{c_{t}\right\}} u\left(c_{t}, h_{t}\right)+\beta \Omega_{t}\left(x_{t}-c_{t}, h_{t}+\lambda\left(c_{t}-h_{t}\right)\right),
$$

and we define the infinite-horizon solution as the limit of the finite horizon solution as the horizon $T$ approaches infinity. ${ }^{21}$

\section{A.3 Optimality Conditions}

\section{A.3.1 The First Order Condition for $c_{t}$}

The first order condition for this problem with respect to $c_{t}$ is:

$$
\begin{aligned}
0 & =P_{t}^{(1-\gamma)(1-\rho)}\left\{u^{c}\left(c_{t}, h_{t}\right)+\beta E_{t}\left(\left(G \tilde{N}_{t+1}\right)^{(1-\gamma-\rho+\rho \gamma)}\left[v_{t+1}^{x} \frac{-R}{G \tilde{N}_{t+1}}+v_{t+1}^{h} \frac{\lambda}{G \tilde{N}_{t+1}}\right]\right)\right\} \\
u^{c}\left(c_{t}, h_{t}\right) & =\beta E_{t}\left[\left(G \tilde{N}_{t+1}\right)^{(\rho \gamma-\gamma-\rho)}\left(R v_{t+1}^{x}-\lambda v_{t+1}^{h}\right)\right] \\
\left(c_{t} h_{t}^{-\gamma}\right)^{-\rho} h_{t}^{-\gamma} & =\beta E_{t}\left[\left(G \tilde{N}_{t+1}\right)^{(\rho \gamma-\gamma-\rho)}\left(R v_{t+1}^{x}-\lambda v_{t+1}^{h}\right)\right] \\
c_{t}^{-\rho} h_{t}^{\gamma(\rho-1)} & =\beta E_{t}\left[\left(G \tilde{N}_{t+1}\right)^{(\rho \gamma-\gamma-\rho)}\left(R v_{t+1}^{x}-\lambda v_{t+1}^{h}\right)\right] \\
c_{t}^{-\rho} & =h_{t}^{\gamma(1-\rho)} \beta E_{t}\left[\left(G \tilde{N}_{t+1}\right)^{(\rho \gamma-\gamma-\rho)}\left(R v_{t+1}^{x}-\lambda v_{t+1}^{h}\right)\right] \\
c_{t} & =h_{t}^{\gamma(1-1 / \rho)}\left\{\beta E_{t}\left[\left(G \tilde{N}_{t+1}\right)^{(\rho \gamma-\gamma-\rho)}\left(R v_{t+1}^{x}-\lambda v_{t+1}^{h}\right)\right]\right\}^{-1 / \rho} \\
c_{t} & \left.=h_{t}^{\gamma(1-1 / \rho)}\left\{\beta\left[\Omega_{t}^{s}-\lambda \Omega_{t}^{h}\right)\right]\right\}^{-1 / \rho}
\end{aligned}
$$

Since we solve the problem backwards from the end of life, at any point $t$ we should have in hand the functions $v_{t+1}^{x}$ and $v_{t+1}^{h}$, so in principle we can solve equation (A.9) to find $c_{t}$ for a grid of possible values of $\left(x_{t}, h_{t}\right)$, yielding values for $v_{t}\left(x_{t}, h_{t}\right), v_{t}^{h}\left(x_{t}, h_{t}\right)$, and $v_{t}^{x}\left(x_{t}, h_{t}\right)$ and so on recursively until the consumption rules have converged.

\footnotetext{
${ }^{21}$ It is necessary to impose some restrictions on parameter values to ensure convergence; see below for a discussion of the necessary assumption.
} 


\section{A.3.2 Applying the Envelope Theorem}

The envelope theorem on the variable $x_{t}$ says:

$$
\begin{aligned}
v_{t}^{x} & =\frac{\partial v_{t}}{\partial x_{t}}+\overbrace{\frac{\partial v_{t}}{\partial c_{t}}}^{=0} \frac{\partial c_{t}}{\partial x_{t}} \\
v_{t}^{x} & =\beta E_{t}\left[\left(G N_{t+1}\right)^{\rho \gamma-\rho-\gamma} R v_{t+1}^{x}\right] \\
v_{t}^{x} & =\beta \Omega_{t}^{s}
\end{aligned}
$$

Thus, equation (A.9) above can be rewritten as

$$
\begin{aligned}
u_{t}^{c} & =v_{t}^{x}-\beta E_{t}\left[\left(G \tilde{N}_{t+1}\right)^{\rho \gamma-\gamma-\rho} \lambda v_{t+1}^{h}\right] \\
v_{t}^{x} & =u_{t}^{c}+\beta E_{t}\left[\left(G \tilde{N}_{t+1}\right)^{\rho \gamma-\gamma-\rho} \lambda v_{t+1}^{h}\right] \\
v_{t}^{x} & =u_{t}^{c}+\lambda \beta \Omega_{t}^{h} .
\end{aligned}
$$

Noting that $\partial h_{t+1} / \partial h_{t}=(1-\lambda) / G N_{t+1}$, the envelope theorem on the variable $h_{t}$ says:

$$
\begin{aligned}
v_{t}^{h} & =\frac{\partial v_{t}}{\partial h_{t}}+\overbrace{\frac{\partial v_{t}}{\partial c_{t}}}^{=0} \frac{\partial c_{t}}{\partial h_{t}} \\
& =u_{t}^{h}+\beta E_{t}\left[\left(G \tilde{N}_{t+1}\right)^{(1-\rho)(1-\gamma)} v_{t+1}^{h} \frac{\partial h_{t+1}}{\partial h_{t}}\right] \\
& =u_{t}^{h}+(1-\lambda) \beta E_{t}\left[\left(G N_{t+1}\right)^{\gamma \rho-\gamma-\rho} v_{t+1}^{h}\right] \\
& =u_{t}^{h}+(1-\lambda) \beta \Omega_{t}^{h}
\end{aligned}
$$

Using the first order conditions (A.14) and (A.15), the problem is solved recursively using numerical methods from the last period of life until successive decision rules have converged, and we denote the converged consumption rule $c\left(x_{t}, h_{t}\right)$.

\section{A.4 Proof that the Multiperiod MPC $\hat{\chi}_{n}$ Reduces to the Single Period MPC $\chi$ for $n=1$ at the Target Level of $c_{t}$}

The goal is to show that

$$
\lim _{\eta \rightarrow 0} \hat{\chi}_{1}\left(k_{t}, \mathcal{H}_{t}, \eta\right)=\chi\left(k_{t}, \mathcal{H}_{t}\right)
$$

if $E_{t}\left[\tilde{c}_{t+1}\right] \approx c_{t}$.

From the definition of $\hat{\chi}_{n}$ in the text (27),

$$
\hat{\chi}_{1}\left(k_{t}, \mathcal{H}_{t}, \eta\right)=E_{t}\left[\frac{C_{t+1} / \tilde{N}_{t+1} \tilde{G}_{t+1}-C_{t}}{P_{t} \eta} \mid P_{t+1}=G_{t+1} P_{t} N_{t+1}(1+\eta)\right] .
$$


Suppressing the conditioning term to reduce clutter and designating the derivatives of $c(x, h)$ with respect to $x$ and $h$ as $c^{x}, c^{h}$, this becomes

$$
\begin{aligned}
\hat{\chi}_{1}\left(k_{t}, \mathcal{H}_{t}, \eta\right) & =E_{t}\left[\frac{\tilde{c}_{t+1} \tilde{P}_{t+1} / \tilde{G}_{t+1} \tilde{N}_{t+1}-c_{t} P_{t}}{P_{t} \eta}\right] \\
= & E_{t}\left[\tilde{c}_{t+1}(1+\eta)-c_{t}\right] / \eta \\
= & E_{t}\left[c\left(\left(R / \tilde{G}_{t+1} \tilde{N}_{t+1}(1+\eta)\right) k_{t}+\tilde{\epsilon}_{t+1}, \mathcal{H}_{t} / \tilde{G}_{t+1} \tilde{N}_{t+1}(1+\eta)\right)(1+\eta)-c_{t}\right] / \eta \\
\approx & E_{t}\left[c\left(\left(R / \tilde{G}_{t+1} \tilde{N}_{t+1}\right)(1-\eta) k_{t}+\tilde{\epsilon}_{t+1},(1-\eta) \mathcal{H}_{t} / \tilde{G}_{t+1} \tilde{N}_{t+1}\right)(1+\eta)-c_{t}\right] / \eta \\
\approx & E_{t}\left[\left(c\left(\left(R / \tilde{G}_{t+1} \tilde{N}_{t+1}\right) k_{t}+\tilde{\epsilon}_{t+1}, \mathcal{H}_{t} / \tilde{G}_{t+1} \tilde{N}_{t+1}\right)\right.\right.
\end{aligned}
$$

Now note that the first term in equation (A.19) is the unconditional expectation of $E_{t}\left[\tilde{c}_{t+1}\left(\tilde{x}_{t+1}, \tilde{h}_{t+1}\right)\right]$ in the normal circumstance where $\eta=0$. By our assumption that the consumer was at the target level of consumption in period $t$, we have $E_{t}\left[\tilde{c}_{t+1}\right]=c_{t}$. Using this fact, equation (A.19) becomes

$$
\begin{aligned}
\hat{\phi}_{1}\left(k_{t}, \mathcal{H}_{t}, \eta\right) \approx E_{t}[ & \left(c\left(\left(R / \tilde{G}_{t+1} \tilde{N}_{t+1}\right) k_{t}+\tilde{\epsilon}_{t+1}, \mathcal{H}_{t} / \tilde{G}_{t+1} \tilde{N}_{t+1}\right)\right. \\
& -\left(R / \tilde{G}_{t+1} \tilde{N}_{t+1}\right) k_{t} c_{t+1}^{x}-\left(\mathcal{H}_{t} / \tilde{G}_{t+1} \tilde{N}_{t+1}\right) c_{t+1}^{h} \\
& \left.\left.-\eta\left[\left(R / \tilde{G}_{t+1} \tilde{N}_{t+1}\right) k_{t} c_{t+1}^{x}-\left(\mathcal{H}_{t} / \tilde{G}_{t+1} \tilde{N}_{t+1}\right) c_{t+1}^{h}\right]\right)\right],
\end{aligned}
$$

and the limit of this expression as $\eta$ goes to zero is equal to the formula for $\chi\left(k_{t}, \mathcal{H}_{t}\right)$ in equation (21).

\section{A.5 Estimating the Time Series Process for $c_{t}$}

The results about the speed with which consumption adjusts toward its 'long run' level in response to a shock to permanent income asserted that the consumption process is well captured by an AR(1). This section presents the basic evidence for that claim.

The precise experiment is as follows. For each combination of parameter values in Tables 6 and 6 , the model is solved for the optimal policy rules and is then simulated for 99 periods in order to allow the population to settle down into something approximating a steady-state. In period 100 the economy is hit by a shock $\eta$ which increases every consumer's permanent income by a factor $1+\eta$ compared to where it would have been in the absence of the shock, where $\eta=0.1$. The simulation then continues until period 200. At the end of the simulations, the following time series process for consumption is estimated:

$$
c_{t}=\alpha+\mu c_{t-1}+\epsilon_{t} .
$$


This equation is the source of the estimated values for the 'AR(1) Coeff.' $\mu$ in Table 6. 


\section{References}

Abel, Andrew B. (1990): "Asset Prices under Habit Formation and Catching Up with the Joneses," American Economic Review, 80(2), 38-42.

(1999): "Risk Premia and Term Premia in General Equilibrium," Journal of Monetary Economics, 43(1), 3-33.

Attanasio, Orazio, Lucio Picci, and Antonello Scorcu (2000): "Saving, Growth, and Investment: A Macroeconomic Analysis Using a Panel of Countries," Review of Economics and Statistics, 82(1).

Blanchard, Olivier J. (1985): "Debt, Deficits, and Finite Horizons," Journal of Political Economy, 93(2), 223-247.

Bosworth, BARry (1993): Saving and Investment in a Global Economy. The Brookings Institution, Washington, DC.

Campbell, John Y., and N. Gregory Mankiw (1991): "The Response of Consumption to Income: A Cross-Country Investigation," European Economic Review, 35, 723-67.

Campbell, John Y., and John H. Cochrane (1999): "By Force of Habit: A Consumption-Based Explanation of Aggregate Stock Market Behavior," Journal of Political Economy, 107(2), 205-251.

Carroll, Christopher D. (1992): "The Buffer-Stock Theory of Saving: Some Macroeconomic Evidence," Brookings Papers on Economic Activity, 1992(2), 61-156.

(1996): "Buffer Stock Saving: Some Theory," Manuscript, Johns Hopkins University, January, http://www.econ.jhu.edu/people/ccarroll/BufferTheory.pdf .

(1997): "Buffer-Stock Saving and the Life Cycle/Permanent Income Hypothesis," Quarterly Journal of Economics, CXII(1), 1-56, http://www.econ.jhu.edu/people/ccarroll/BSLCPIH.pdf .

(1999): "Precautionary Saving and the Marginal Propensity to Consume Out of Permanent Income," Manuscript, Johns Hopkins University.

— (2000): "Solving Consumption Models with Multiplicative Habits," Forthcoming, Economics Letters, http://www.econ.jhu.edu/people/ccarroll/HabitsEconLett.pdf .

Carroll, Christopher D., and Miles S. Kimball (1996): "On the Concavity of the Consumption Function," Econometrica, 64(4), 981-992, http://www.econ.jhu.edu/people/ccarroll/concavity.pdf . 
Carroll, Christopher D., Jody R. Overland, and David N. Weil (2000): "Saving and Growth with Habit Formation," American Economic Review, 90(3), 1-15, http://www.econ.jhu.edu/people/ccarroll/AERHabits.pdf .

Carroll, Christopher D., and Lawrence H. Summers (1991): "Consumption Growth Parallels Income Growth: Some New Evidence," in National Saving and Economic Performance, ed. by B. Douglas Bernheim, and John B. Shoven. Chicago University Press, Chicago.

Carroll, Christopher D., and David N. Weil (1994): "Saving and Growth: A Reinterpretation," Carnegie-Rochester Conference Series on Public Policy, 40, 133192.

Constantinides, George M. (1990): "Habit Formation: A Resolution of the Equity Premium Puzzle," Journal of Political Economy, 98, 519-43.

Deaton, Angus S. (1991): "Saving and Liquidity Constraints," Econometrica, 59, 12211248.

(1992): Understanding Consumption. Oxford University Press, New York.

Deaton, Angus S., and Christina H. Paxson (1997): "The Effects of Economic and Population Growth on National Saving and Inequality," Demography, 34(1), 97-114.

- (2000): "Saving and Growth: Another Look at the Cohort Evidence," Review of Economics and Statistics, 82(1).

Fuhrer, Jeffrey C. (2000): "An Optimizing Model for Monetary Policy: Can Habit Formation Help?," American Economic Review, 90(3).

Fuhrer, Jeffrey C., and Michael W. Klein (1998): "Risky Habits: On Risk Sharing, Habit Formation, and the Interpretation of International Consumption Correlations," NBER Working Paper No. 6735.

Hayashi, Fumio (1986): "Why Is Japan's Saving Rate So Apparently High?," in NBER Macroeconomics Annual, 1986. NBER, Cambridge.

- (1997): Understanding saving : evidence from the United States and Japan. The MIT Press, Cambridge, Mass.

Horioka, Charles Y. (1997): "A Cointegration Analysis of the Impact of the Age Structure of the Population on the Household Saving Rate in Japan," Review of Economics and Statistics, 79(3), 511-516.

Horioka, Charles Y., and Wako Watanabe (1997): "Why Do People Save? A Micro-Analysis of Motives for Household Saving in Japan," Economic Journal, 107(442), 537-552. 
Jermann, Urban J. (1998): “Asset Pricing in Production Economies," Journal of Monetary Economics, 42(2), 257-75.

Kimball, Miles S. (1990): "Precautionary Saving and the Marginal Propensity to Consume," NBER Working Paper Number 3403.

Krusell, Per, and Anthony A. Smith (1998): "Income and Wealth Heterogeneity in the Macroeconomy," Journal of Political Economy, 106(5), 867-896.

Loayza, Norman, Klaus Schmidt-Hebbel, and Luis Servén (2000): "What Drives Saving Across the World?," Review of Economics and Statistics, 82(1).

RoDRIK, DAnI (1999): "Saving Transitions," Manuscript, Harvard University.

Tobin, James (1967): "Life Cycle Saving and Balanced Growth," in Ten Economic Studies in the Tradition of Irving Fisher, ed. by William Fellner. Wiley, New York.

Viard, A. (1993): "The Productivity Slowdown and the Savings Shortfall: A Challenge to the Permanent Income Hypothesis," Economic Inquiry, 31, 549-564. 